Article

\title{
Estimation of Water Level Changes of Large-Scale Amazon Wetlands Using ALOS2 ScanSAR Differential Interferometry
}

\author{
Ning Cao ${ }^{1,2}\left(\mathbb{D}\right.$, Hyongki Lee ${ }^{1,2, *}$, Hahn Chul Jung ${ }^{3}$ and Hanwen $\mathrm{Yu}^{1,2}$ \\ 1 Department of Civil \& Environmental Engineering, University of Houston, Houston, TX 77004, USA; \\ ncao5@uh.edu (N.C.); yuhanwenxd@gmail.com (H.Y.) \\ 2 National Center for Airborne Laser Mapping, Houston, TX 77204 USA \\ 3 Hydrological Sciences Laboratory, NASA Goddard Space Flight Center, Science Systems and Applications, \\ Inc., Lanham, MD 20706, USA; hahnchul.jung@gmail.com \\ * Correspondence: hlee@uh.edu
}

Received: 23 May 2018; Accepted: 15 June 2018; Published: 17 June 2018

\begin{abstract}
Differential synthetic aperture radar (SAR) interferometry (DInSAR) has been successfully used to estimate water level changes $(\partial \mathrm{h} / \partial \mathrm{t})$ over wetlands and floodplains. Specifically, amongst ALOS PALSAR datasets, the fine-beam stripmap mode has been mostly implemented to estimate $\partial \mathrm{h} / \partial \mathrm{t}$ due to its availability of multitemporal images. However, the fine-beam observation mode provides limited swath coverage to study large floodplains and wetlands, such as the Amazon floodplains. Therefore, for the first time, this paper demonstrates that ALOS2 ScanSAR data can be used to estimate the large-scale $\partial \mathrm{h} / \partial \mathrm{t}$ in Amazon floodplains. The basic procedures and challenges of DInSAR processing with ALOS2 ScanSAR data are addressed and final $\partial \mathrm{h} / \partial \mathrm{t}$ maps are generated based on the Satellite with ARgos and ALtiKa (SARAL) altimetry's reference data. This study reveals that the local $\partial \mathrm{h} / \partial \mathrm{t}$ patterns of Amazon floodplains are spatially complex with highly interconnected floodplain channels, but the large-scale (with $350 \mathrm{~km}$ swath) $\partial \mathrm{h} / \partial \mathrm{t}$ patterns are simply characterized by river water flow directions.
\end{abstract}

Keywords: SAR; InSAR; DInSAR; water level change; floodplain; wetland

\section{Introduction}

The wetlands and floodplains of the Amazon River are massive in size and in volumetric fluxes. The Amazon Basin, with an area of $\sim 6$ million $\mathrm{km}^{2}$ and containing the largest tropical rainforest in the world, contributes $15 \%-20 \%$ of the global river discharge to the oceans (annual averaged discharge of $\sim 200,000 \mathrm{~m}^{3} \mathrm{~s}^{-1}$ ) [1,2]. Basin-wide hydrologic and hydrodynamic modeling suggests that surface water accounts for most of the Amazon's total storage (56\%), followed by soil water $(27 \%)$ and ground water (8\%) [3]. Therefore, the amount of water on the Amazon floodplains and wetlands and the amount exchanged with river channels become essential information for understanding large-scale flood propagation, sediment delivery and nutrient exchanges, and the emission of methane and carbon dioxide [4-12]. However, measuring storage and its flux using in situ stage recording devices is not effective because its water flow is complex and not bounded, as in typical channel flow. Consequently, the data scarcity and complexity of the hydrological process still remain a challenge to fully understand the hydrologic dynamics of seasonally flooded wetlands and floodplains [13-15].

Given the vast size and remote location of this large tropical basin, satellite-borne observations (such as radar imaging and satellite altimetry) provide the only viable approach to understanding the spatial and temporal distributions of its water balances and to constraining and validating 
basin-scale hydrologic and hydrodynamic models. Among the various remote sensing technologies, differential synthetic aperture radar (SAR) interferometry (DInSAR) has been proven to be a useful technique for measuring ground displacement $[16,17]$. It has also been used to estimate water level changes $(\partial \mathrm{h} / \partial \mathrm{t})$ in floodplains and wetlands [18-25]. The rationale of using DInSAR to measure $\partial \mathrm{h} / \partial \mathrm{t}$ is based on the fact that the vegetation and water surface create a double-bounce scattering mechanism [26]. The strength of the double-bounce scatterings depends on factors such as aboveground biomass levels, canopy structure, and water levels [27]. A detailed analysis of the connections between the biomass levels and double-bounce scattering can be found in [28-30]. A theoretical analysis of the canopy backscatter modeling of the floodplain can also be found in [31]. When the water surface rises or falls, the range from the radar to the double-bounce scatterers changes, which can be captured by DInSAR. In other words, vegetation is needed to measure $\partial \mathrm{h} / \partial \mathrm{t}$. For still open water, the backscattering signal would reflect away from the radar and no measurements can be obtained. For open water with waves, correlation is generally lost for DInSAR because of the temporal randomness of the waves. The SAR data from the Space Shuttle Imaging Radar mission (SIR-C) was first used to estimate $\partial \mathrm{h} / \partial \mathrm{t}$ in Amazon floodplains [18]. In recent years, L-band JERS data and ALOS PALSAR data have also been used to estimate $\partial \mathrm{h} / \partial \mathrm{t}$ in both Congo and Amazon floodplains [21-25]. The unwrapped differential interferograms can provide only a spatial gradient of $\partial \mathrm{h} / \partial \mathrm{t}$. Therefore, a vertical reference (or an offset) is needed to convert it into absolute $\partial \mathrm{h} / \partial \mathrm{t}$. Recently, satellite altimetry has been used as the vertical reference in order to generate "absolute" $\partial \mathrm{h} / \partial \mathrm{t}$ maps [21,24-32]. The Satellite with ARgos and ALtiKa (SARAL) altimetry measurements are used as a reference in this study. The SARAL altimeter is a Ka-band system with repetivity of 35 days [33].

All of the above previous studies only focus on a small portion of the floodplains using fine-beam data. For PALSAR fine-beam mode, the observation swath is around $70 \mathrm{~km}$, which is too small to study large floodplains and wetlands, such as the Amazon floodplains. Figure 1 shows the study area of the Amazon floodplains with PALSAR wrapped fine-beam differential interferograms. The master-slave acquisition dates (yyyymmdd) for the six swaths from left to right are 20100430-20100615, 20100529-20100714, 20100512-20100627, 20100425-20100610, 20100524-20100709, and 20100507-20100622, respectively. It can be seen that at least six swaths (each with five to six frames) are needed to cover the entire study area. However, the repeat time of the PALSAR system is 46 days and the basic observation scenarios are designed to be provided three times per year for global coverage for fine-beam mode in order to meet the requirements of a multitude of users [34]. It has been found that there are approximately only three to four acquisitions for the same area during the flood season of Amazon wetlands between February and July. In other words, only two to three $\partial \mathrm{h} / \partial \mathrm{t}$ maps can be generated for every flood season, which is not efficient since $\partial \mathrm{h} / \partial \mathrm{t}$ changes rapidly in Amazon floodplains. Besides the temporal variations, the large-scale spatial $\partial \mathrm{h} / \partial \mathrm{t}$ patterns also cannot be directly analyzed using PALSAR fine-beam datasets. For example, six swaths of the interferograms generated from different time spans can be mosaicked in Figure 1 to cover the entire study area. However, the large-scale $\partial \mathrm{h} / \partial \mathrm{t}$ patterns cannot be directly analyzed since the six segments are from different temporal spans. Therefore, the small coverage and large repeat time constrain the applications of PALSAR fine-beam data to study the large-scale $\partial \mathrm{h} / \partial \mathrm{t}$ of Amazon floodplains.

Besides PALSAR fine-beam data, ScanSAR data has also been used to study the hydrologic dynamics of large scale wetlands, such as hydroperiod estimation and flood extent monitoring $[35,36]$. Moreover, PALSAR ScanSAR data can also be used to estimate $\partial \mathrm{h} / \partial \mathrm{t}$ in Amazon wetlands as shown in Figure 2a. It can be seen that the pattern of $\partial \mathrm{h} / \partial \mathrm{t}$ for most of the study area can be obtained. The ALOS ScanSAR mode has a swath of $350 \mathrm{~km}$ with basic observation scenario of eight times per year for wetland focus areas. Therefore, the routine use of ScanSAR data for DInSAR processing can significantly improve our understanding of $\partial \mathrm{h} / \partial \mathrm{t}$ in Amazon floodplains and wetlands. The most critical challenge in processing ALOS ScanSAR for DInSAR is the synchronization of the signal bursts [37]. The basic idea of synchronization is that the scene should be viewed from the same 
azimuth angle by corresponding pulses to acquire enough coherence. Since the synchronization of the bursts is not well programmed in ALOS PALSAR mission, the burst overlap is not always large enough for interferometric analysis, which limits the DInSAR processing. We have found that only a few ALOS ScanSAR pairs can acquire reliable $\partial \mathrm{h} / \partial \mathrm{t}$ for the study area.

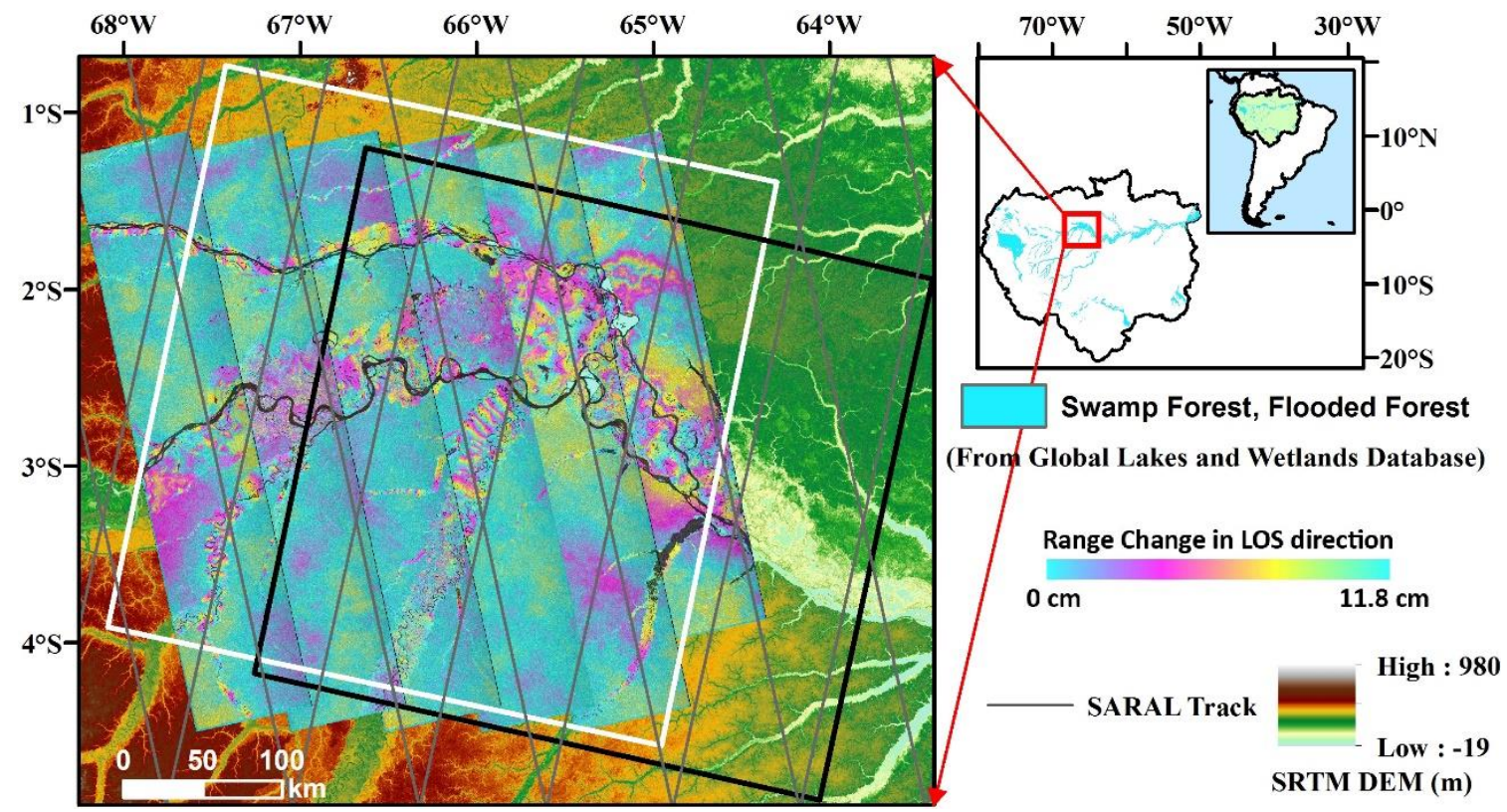

Figure 1. Study areas of Amazon floodplains with ALOS PALSAR fine-beam wrapped differential interferograms acquired between April and July 2010. Each fringe represents about $12 \mathrm{~cm}$ of water level changes in line-of-sight (LOS) direction. Black and white rectangles are the coverage of the ALOS PALSAR ScanSAR and ALOS2 PALSAR2 ScanSAR datasets used in this study.
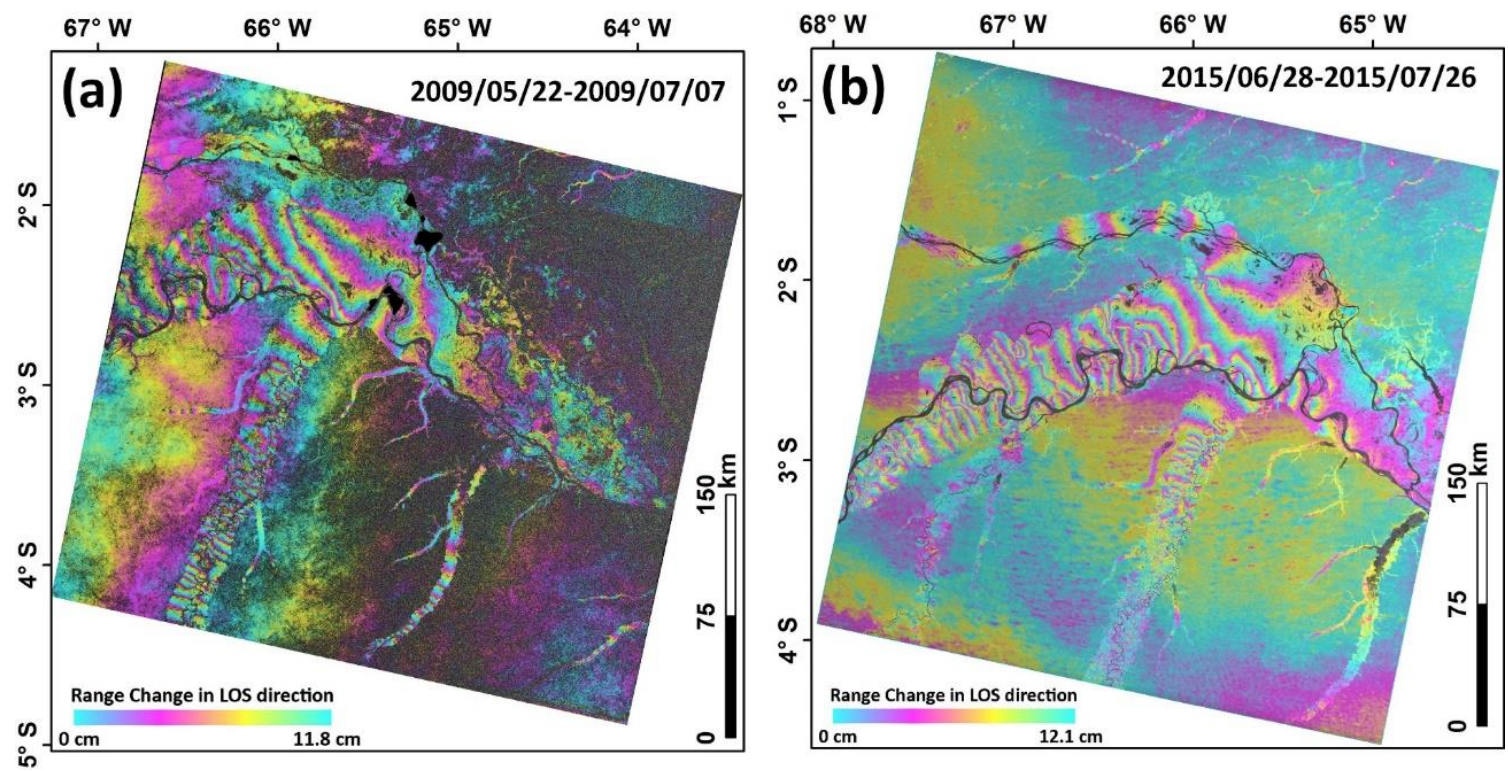

Figure 2. ScanSAR wrapped differential interferograms. (a) ALOS PALSAR ScanSAR with acquisition dates of 20090522-20090707; (b) ALOS2 ScanSAR with acquisition dates of 20150628-20150726.

Since the launch of the ALOS2 PALSAR2 system, ALOS2 ScanSAR data has become available to estimate $\partial \mathrm{h} / \partial \mathrm{t}$ in Amazon floodplains. The PALSAR2 system is a significant upgrade of the 
PALSAR radar. The synchronization of the bursts has been well planned for repeat-pass interferometry. An example of a repeat-pass interferogram is demonstrated in Figure 2b. ALOS2 ScanSAR has a swath of $350 \mathrm{~km}$ with basic observation scenarios of around nine times per year for wetland monitoring, which means four to five $\partial \mathrm{h} / \partial \mathrm{t}$ measurements for Amazon floodplains during the flood season.

Because of the dense canopy in Amazon floodplains, only L-band (or P-band) signals can sufficiently penetrate the canopy and reach the water surface. Among the available space-borne SAR missions, L-band SAR systems are preferred to measure $\partial \mathrm{h} / \partial \mathrm{t}$ in Amazon floodplains. Besides the historical JERS, ALOS, and currently operating ALOS2 systems, several L-band SAR systems are planned to be launched in the future, such as the Tandem-L and NISAR systems [38,39]. Hitherto, only ALOS2 ScanSAR data can be used currently to estimate $\partial \mathrm{h} / \partial \mathrm{t}$ in large-scale Amazon floodplains. None of the previous studies have been conducted to estimate $\partial \mathrm{h} / \partial \mathrm{t}$ of Amazon wetlands with ALOS2 ScanSAR DInSAR. Therefore, for the first time, this paper demonstrates that ALOS2 ScanSAR data can be used to map and analyze $\partial \mathrm{h} / \partial \mathrm{t}$ in Amazon floodplains.

This paper is organized as follows. The basic procedures and challenges of DInSAR processing with ALOS2 ScanSAR data are given and discussed in Section 2. Section 3 provides the results and discussions on $\partial \mathrm{h} / \partial \mathrm{t}$ patterns and the final $\partial \mathrm{h} / \partial \mathrm{t}$ maps. We conclude with Section 4 which summarizes our findings.

\section{Data Processing Strategy}

In this section, the DInSAR approach using ALOS2 ScanSAR data is introduced to estimate $\partial \mathrm{h} / \partial \mathrm{t}$, where the SARAL $40 \mathrm{~Hz}$ Sensor Geophysical Data Record (SGDR) dataset of year 2015 are used to provide references.

\subsection{SAR Dataset Used}

The ALOS2 ScanSAR datasets with $\mathrm{HH}$ polarization acquired during the flood season (i.e., between February to July) of 2015 were used to estimate the large-scale $\partial \mathrm{h} / \partial \mathrm{t}$ in the Amazon floodplains. The ALOS2 datasets used in this study are summarized in Table 1. The perpendicular baselines of the four pairs are relatively small, which means the interferometry is less affected by the geometrical decorrelation. In order to analyze $\partial \mathrm{h} / \partial \mathrm{t}$ patterns for different periods, adjacent scanning pairs were combined to perform DInSAR. Such a configuration can also reduce the effect of temporal decorrelation. The 30-m resolution Shuttle Radar Topography Mission (SRTM) DEM was used in the DInSAR procedure.

Table 1. ALOS2 ScanSAR datasets used in this study.

\begin{tabular}{ccc}
\hline Master-Slave Dates (yyyymmdd) & Perpendicular Baseline $(\mathbf{m})$ & Incidence Angle $\mathbf{(}^{\circ}$ ) \\
\hline $20150222-20150405$ & 111 & 39 \\
$20150405-20150517$ & 21 & 39 \\
$20150517-20150628$ & 209 & 39 \\
$20150628-20150726$ & 159 & 39 \\
\hline
\end{tabular}

Note: The perpendicular baselines and incidence angles are obtained from the third swaths of the ScanSAR datasets.

\subsection{Basic Procedures of ScanSAR DInSAR Processing}

A flowchart of ALOS2 ScanSAR DInSAR processing is shown in Figure 3. The input single-look-complex (SLC) images were level 1.1 full-aperture images, which means the ScanSAR bursts were processed by a stripmap processor by filling burst gaps with zero echoes before focusing. The major advantage of using the full-aperture image is that existing stripmap InSAR processors can still be used. Every SLC dataset contains five subswath images, each of which were processed individually before mosaicking. 


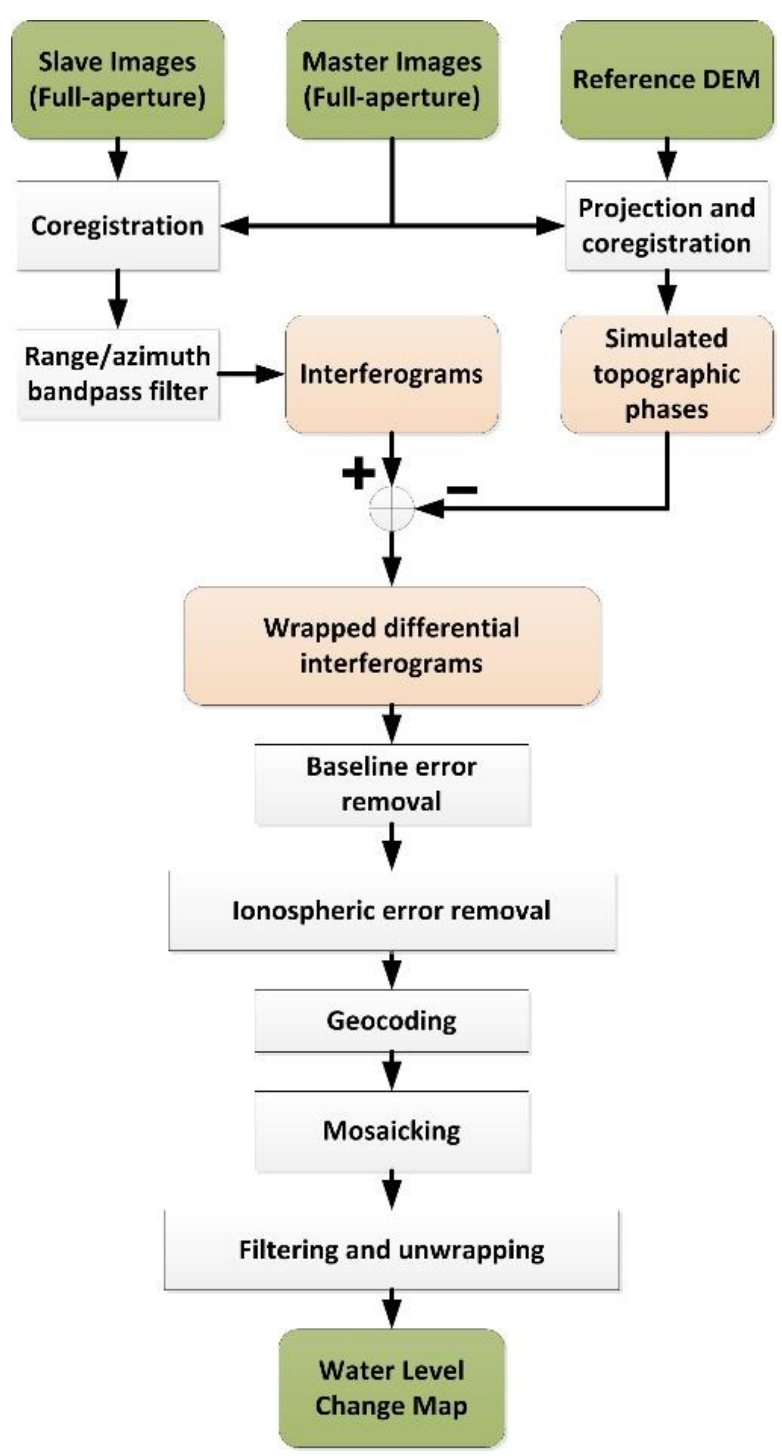

Figure 3. Flowchart of ALOS2 ScanSAR DInSAR processing.

Compared with conventional DInSAR processing with stripmap mode data, DInSAR processing with ALOS2 ScanSAR mode data is more complicated and special cautions are needed [40]. The major difference is the removal of the nonoverlap spectrum caused by burst misalignment. First, the cross-correlation was used to estimate the offsets between master and slave SLC images, and slave SLC was coregistered to the master grid by resampling. After coregistration, the common range and azimuth spectrums of master and slave SLC images were estimated and extracted by bandpass filters separately. Once we obtained two SLC images with overlap spectrums, an interferogram was obtained and the topographic phase contribution was removed using a reference digital elevation model (DEM) to generate a differential interferogram. In many cases, residual phases caused by baseline error and ionospheric error existed and needed to be removed. Then, the five differential interferograms were geocoded and mosaicked. Finally, a deformation map was generated after filtering and unwrapping.

\subsection{Coregistration}

It has been found that the cross-correlation coregistration method used in stripmap mode InSAR can also be used to coregister full-aperture ScanSAR images [41]. For an InSAR pair, the offsets 
between master and slave images are estimated using cross-correlation. Then, the offsets are parameterized by a low-order polynomial function of range and azimuth using least-squares curve fitting. Finally, the slave image is resampled to the master coordinate system using the polynomial function. Compared with the stripmap mode image, the azimuth pixel number of ScanSAR image is much larger than range pixel number. For example, in this study, the azimuth pixel number was usually 20-times larger than the range pixel number. Moreover, ScanSAR InSAR requires very high azimuth coregistration precision. Therefore, it is necessary to acquire more offset measurements in azimuth direction than range direction. In this study, the number of offset measurements in azimuth and range directions were set to be 64 and 512, respectively.

\subsection{Baseline Error Removal}

As shown in Figure 3, the topographic phases are estimated from baselines and external DEM. In order to avoid discontinuity between subswaths in ScanSAR DInSAR, only the orbit information was used to estimate the topographic phases. Because of the inaccurate orbit measurement, residual phases caused by baseline error could exist in the final differential interferograms. The baseline error can be estimated and removed by fitting the residual phase interferogram by predefined polynomial models. First, the differential interferogram should be unwrapped. The unwrapped results are fitted by a low-order polynomial function of range and azimuth using the least-squares method. After the estimation of the optimal parameters, the estimated residual phase is subtracted from the differential interferogram. For example, the wrapped differential interferograms before and after baseline error removal are shown in Figure 4. It can be seen that the baseline phase error component has been successfully removed after the baseline error removal. It should be noted that the floodplains with water level changes should be masked out in the above procedure. Moreover, the baseline error removal can also be implemented after geocoding and mosaicking the five subswaths to avoid steps between subswaths.
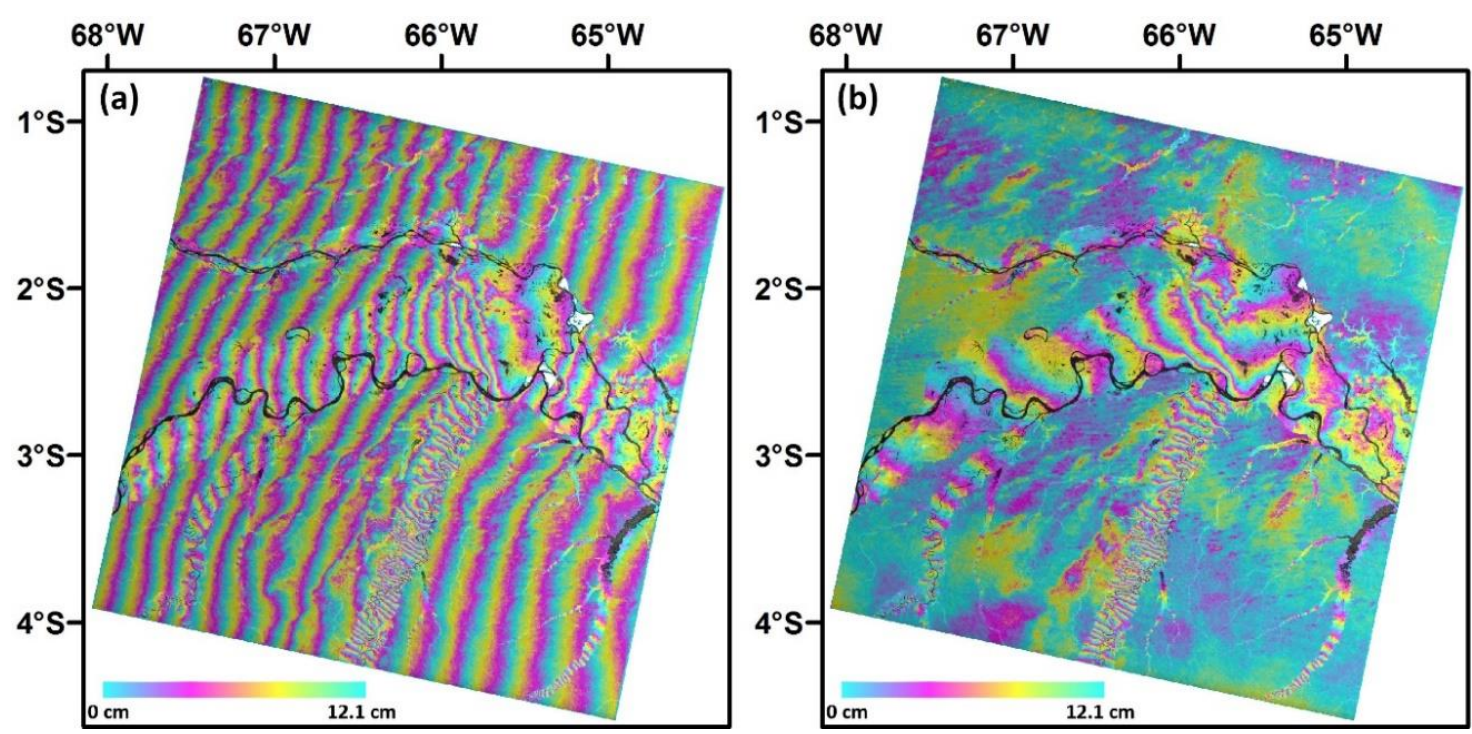

Figure 4. Wrapped differential interferograms of 20150517-20150628 pair before (a) and after (b) baseline error removal.

\subsection{Ionospheric Error Removal}

It is known that the phase of the radar pulse would be advanced when a radar pulse propagates through the ionosphere. The ionospheric phase distortion in radar images is proportional to the total electron content (TEC) and the inverse of the radar frequency [42,43]. The L-band SAR systems are more sensitive to the ionospheric phase distortions than the X-and C-band SAR systems. 
Moreover, the ionospheric phase error can be particularly severe in three main regions including equatorial (such as the Amazon floodplains), middle, and high latitude regions [44,45]. In recent years, various ionospheric correction methods have been proposed for DInSAR processing [45-50]. These methods can generally be divided into two main categories: (1) the range split-spectrum methods are based on the dispersive propagation of the ionosphere to estimate the difference of the phase delay from different wavelengths [45-51]; (2) the azimuth shift methods are based on the proportional relation between azimuth displacement and azimuth derivative of the ionospheric phases [52-54]. The azimuth displacement can be estimated by accurate coregistration or multiple-aperture interferometry (MAI) $[53,54]$. The ionospheric phase screen can then be obtained by integrating the scaled azimuth shift in the azimuth direction. In this study, the MAI-based azimuth shift method was used to estimate the ionospheric errors. As shown in Figure 5, a segment of the fifth subswath of pair 20150222-20150405 was used to demonstrate the ionospheric correction. It can be seen from Figure 5a that the upper-right area shows clear ionospheric distortions. Using an azimuth common band filter, the full aperture can be split into two looks (forward- and backward-looks) for both master and slave datasets and corresponding interferograms can be generated. As shown in Figure 5b, the MAI interferogram can then be obtained from the conjugate multiplication of the forward- and backward-looking interferograms. The streaks shown in Figure $5 \mathrm{~b}$ are mainly caused by the ionospheric TEC variation. As shown in Figure $5 c$, the ionospheric phase screen can be generated by integrating the scaled MAI interferogram in azimuth direction. Finally, the corrected interferogram can be obtained by subtracting the ionospheric phase screen from the original interferogram. It can be seen from Figure $5 \mathrm{~d}$ that the ionospheric distortions have been effectively removed, especially in the upper-right area.
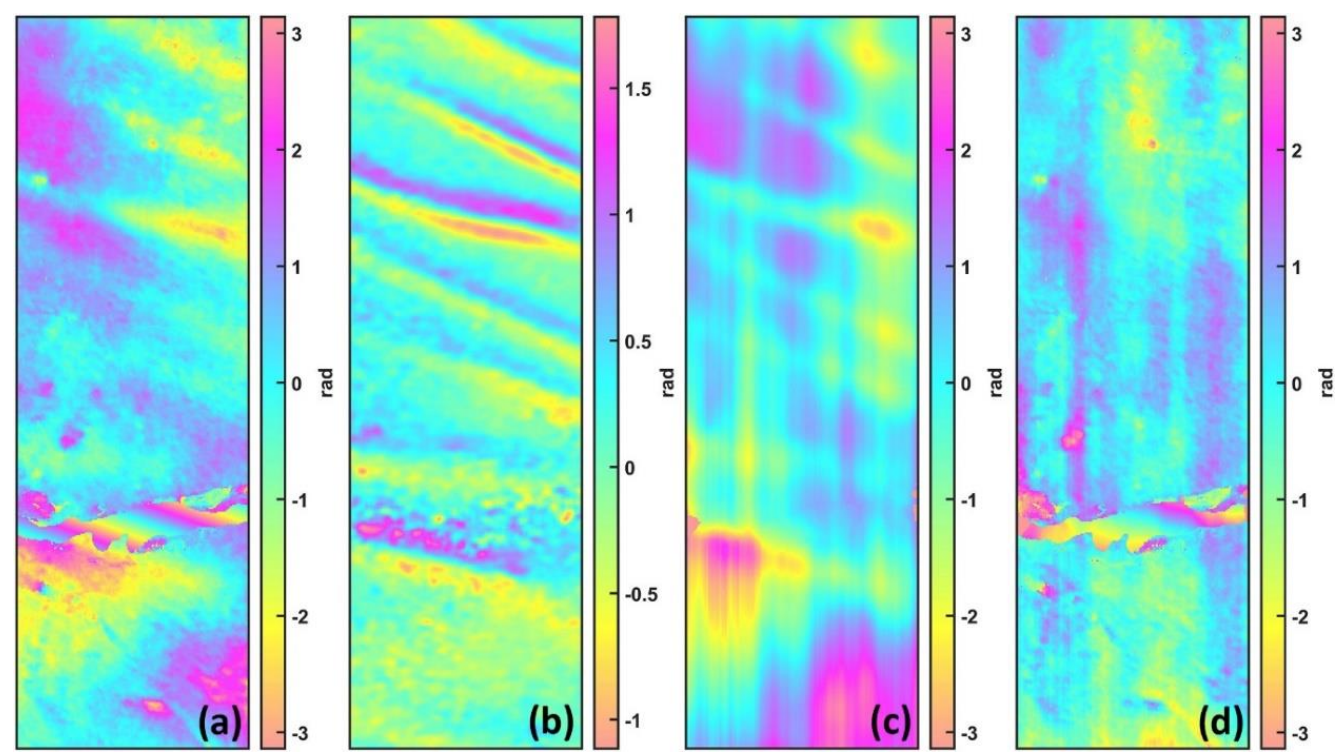

Figure 5. Ionospheric correction results. (a) Original differential interferogram; (b) MAI interferogram; (c) Ionospheric phase screen; (d) Corrected interferogram.

Besides ionospheric TEC variation, ground deformation can also cause residual phases in the MAI interferogram. In this study, the floodplains with water level changes were masked out to estimate the ionospheric phase screen. Then, the ionospheric phases for the masked-out area were interpolated. However, if the ionospheric distortions vary significantly in the floodplains, the interpolation of the ionospheric phases becomes unreliable. Moreover, the numerical integration can introduce a numerical error that grows as azimuthal distance increases, which could cause phase ramps in the final result. Therefore, the ionospheric correction may not be correctly implemented, especially for noisy data with low coherence. In this study, it was a challenge to entirely remove the ionospheric error, something which requires more work in the future. 


\subsection{Phase Unwrapping}

For DInSAR processing, phase unwrapping is a critical step, especially for areas with strong phase variations. For single-baseline phase unwrapping, the phase jumps between adjacent pixels are assumed to be smaller than $\pi$ and the phase can be unwrapped by integrating the phase gradient among adjacent pixels. However, phase unwrapping encounters difficulties when the phase jumps are larger than $\pi$. In this study, phase discontinuities mainly existed in two cases: the border between floodplain and nonfloodplain areas, and the border between different floodplain segments separated by channels.

For example, a segment of the wrapped differential interferogram of pair 20150628-20150726 is shown in Figure 6a. It can be seen that the fringes generally change along the river flow direction and the phase jumps are clear along the borders of the floodplains. In this study, the branch-cut region growing algorithm was used to perform phase unwrapping [55,56]. Directly performing phase unwrapping would cause discontinuities in the final results, as shown in Figure $6 \mathrm{~b}$. The phase discontinuities are caused by the inappropriate formations of the branch-cuts that join the residues. In other words, the phase unwrapping integration path should climb the "hill" (i.e., along the direction of the river) in order to avoid phase jumps. However, the default strategy of the current branch-cut algorithm would not automatically guarantee such an integration path. Moreover, the floodplains are separated into different segments by the channels, which also causes phase discontinuities.
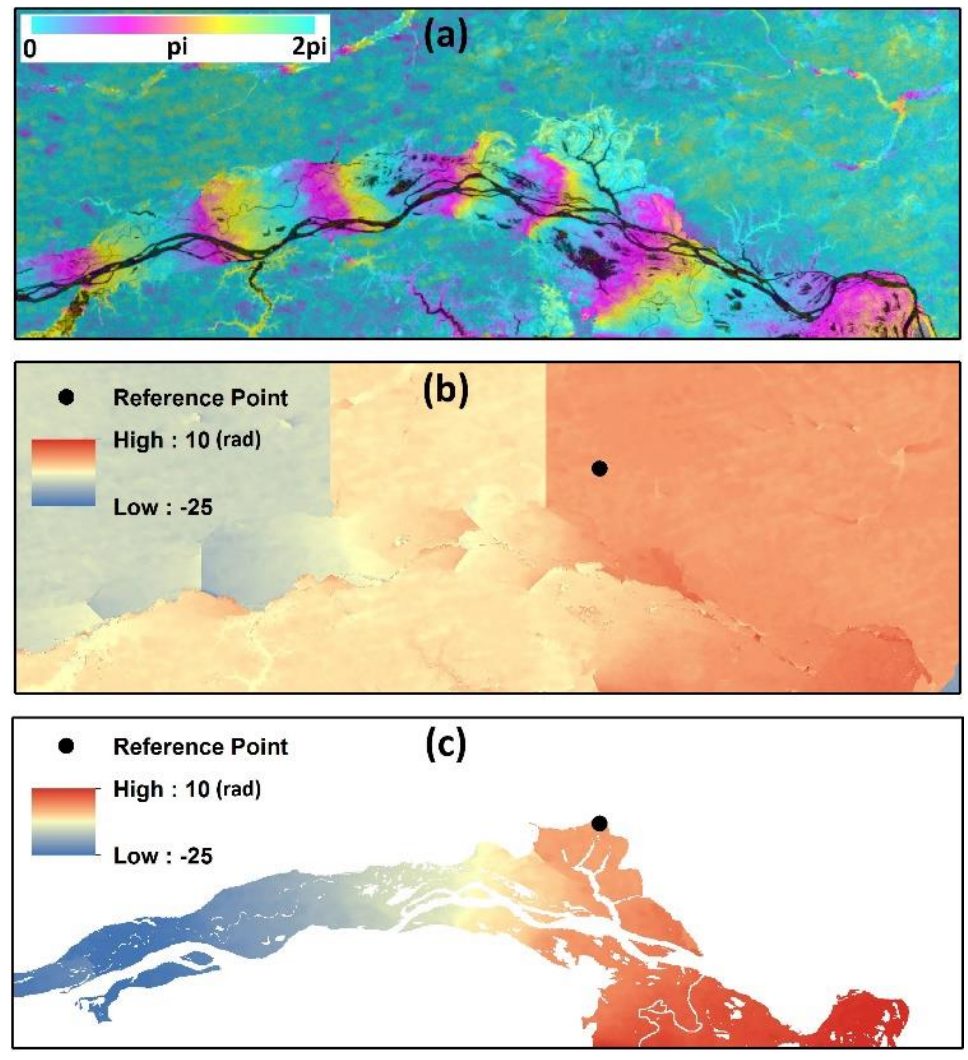

Figure 6. (a) A segment of wrapped differential interferogram of pair 20150628-20150726; (b) Unwrapped result without masking; (c) Unwrapped result with masking. The black dots are the reference point (with phase set to be zero) for phase unwrapping.

Therefore, we extracted the floodplain area by masking out upland areas from the original interferogram and then performed phase unwrapping. Since the floodplain is separated into several disconnected regions by the river, we performed unwrapping for individual segments and then connected them to get the final results, as shown in Figure $6 c$. The connection can be easily implemented 
by adding an offset value if assuming the phase jump between adjacent segments is less than $\pi$. The connection of disconnected areas is straightforward in Figure 6, since the pattern of the fringes is clear and simple (i.e., the phase jump between adjacent segments is less than $\pi$ ). However, there exist cases when the phase jumps are larger than $\pi$ and the connection of different segments can be incorrect. Moreover, a reference is needed to obtain the absolute $\partial \mathrm{h} / \partial \mathrm{t}$ measurements. In this study, we used SARAL altimetry measurements as references to correct the phase jumps between disconnected areas. Another potential way to deal with the large phase jumps is by using multibaseline phase unwrapping methods [57,58], which will be tested in the future.

\section{Results and Discussion}

\subsection{Results of SARAL Altimetry}

The SRTM DEM over the study area is shown in Figure 7 along with 16 segments of tracks of the SARAL altimetry used in this study. It is easy to see that the topography generally decreases from upstream to downstream. Besides the Amazon mainstem, the floodplains of the three tributaries (i.e., Japura River, Jutai River, and Jurua River) are also included in this study area. From the SARAL altimetry measurement, the water levels of the floodplains of the four rivers can be obtained as shown in Figure 8. The water levels are obtained by spatially averaging the track segments. From Figure 8a, we can see that the water levels decrease from segment (1) to (8), which is expected since the topography decreases from segment (1) to (8). We can also see that the mainstem floodplains generally reach peak water levels between May and June. Compared with the mainstem, the three tributaries reach peak water levels at slightly different times, especially in the case of the Japura River. We can see from Figure $8 \mathrm{~b}$ that the Japura River reaches its peak water level at the end of June. The offsets between two lines in Figure 8c,d can be caused by the topographic differences between different tracks. Generally speaking, the water level increases before June and starts to fall after June over the study area. Even though satellite altimetry can successfully measure the water level changes, the measurements are limited to the 1-D track and it is difficult to analyze the spatial pattern of $\partial \mathrm{h} / \partial \mathrm{t}$. Therefore, it is necessary to use DInSAR to acquire the 2-D $\partial \mathrm{h} / \partial \mathrm{t}$ maps.

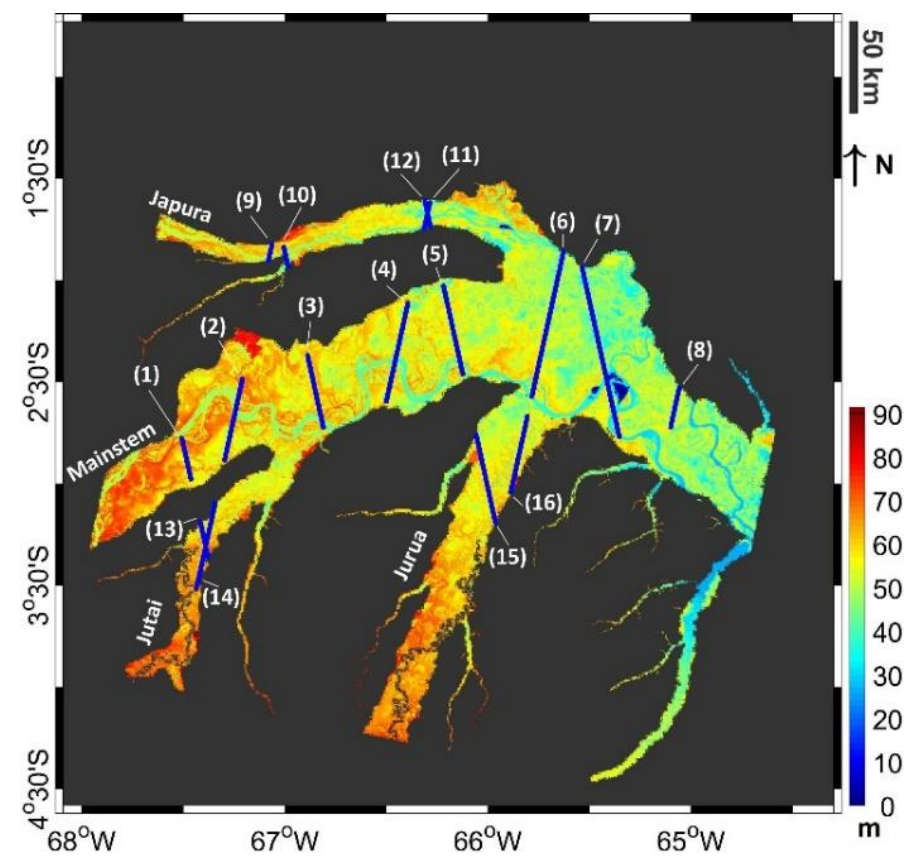

Figure 7. SRTM DEM of the study area. Blue lines indicate segments of the SARAL altimetry tracks used in this study. 

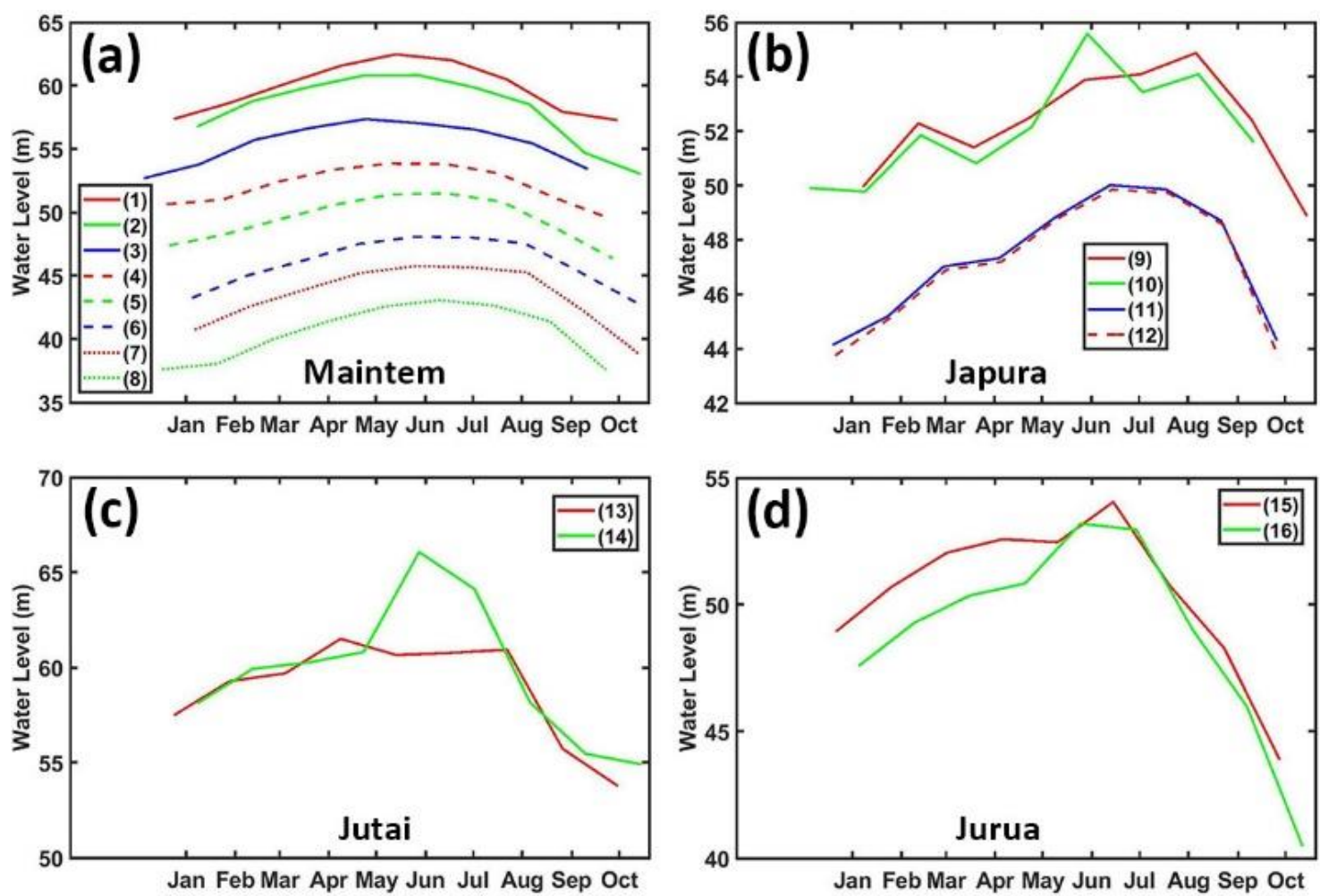

Figure 8. Water levels measured by SARAL altimetry for year 2015. (a-d) indicates the floodplains of the four rivers. Labels (1)-(16) indicate the 16 segments of the altimetry tracks as shown in Figure 7. For every segment, the altimetry water levels are averaged.

\subsection{Interpretations of $\partial h / \partial t$ Patterns on a Small Scale}

The final ALOS2 ScanSAR differential interferograms are obtained as shown in Figure 9. Three segments of the study area are zoomed in to interpret the $\partial \mathrm{h} / \partial \mathrm{t}$ patterns on a small scale, as shown in Figure 10. It should be noted that there still exist some residual phases caused by ionospheric errors, especially for Figure $9 \mathrm{a}, \mathrm{b}$. However, such residual phases generally do not affect the analysis of the spatial patterns of $\partial \mathrm{h} / \partial \mathrm{t}$ maps. From the altimetry measurements in Figure 8 , it is known that water rises from February to mid-May (i.e., Figure $9 a, b$ ) and begins to fall at the end of June (i.e., Figure $9 c, d)$. Several key interpretations of $\partial \mathrm{h} / \partial \mathrm{t}$ patterns can be obtained from Figures 9 and 10.

First, the patterns of $\partial \mathrm{h} / \partial \mathrm{t}$ vary significantly as the water level changes. At the mid-rising water period (i.e., Figure $9 \mathrm{a}, \mathrm{b}), \partial \mathrm{h} / \partial \mathrm{t}$ tends to be localized and related to the topography of scroll bars, levees, channels, and depressions, which is consistent with the previous studies [22]. At the high water period (i.e., Figure 9c), the mainstem floodplain has smooth $\partial \mathrm{h} / \partial \mathrm{t}$ patterns extended uniformly across the floodplain, which means the water is flowing in a diffuse pattern. At the mid-falling water period (i.e., Figure $9 \mathrm{~d}$ ), $\partial \mathrm{h} / \partial \mathrm{t}$ patterns of the mainstem floodplain become complex and localized again. In Figure $9 \mathrm{~d}$, the $\partial \mathrm{h} / \partial \mathrm{t}$ pattern of the Japura floodplain becomes uniformly extended since Japura River reaches its peak water level at the end of June. 

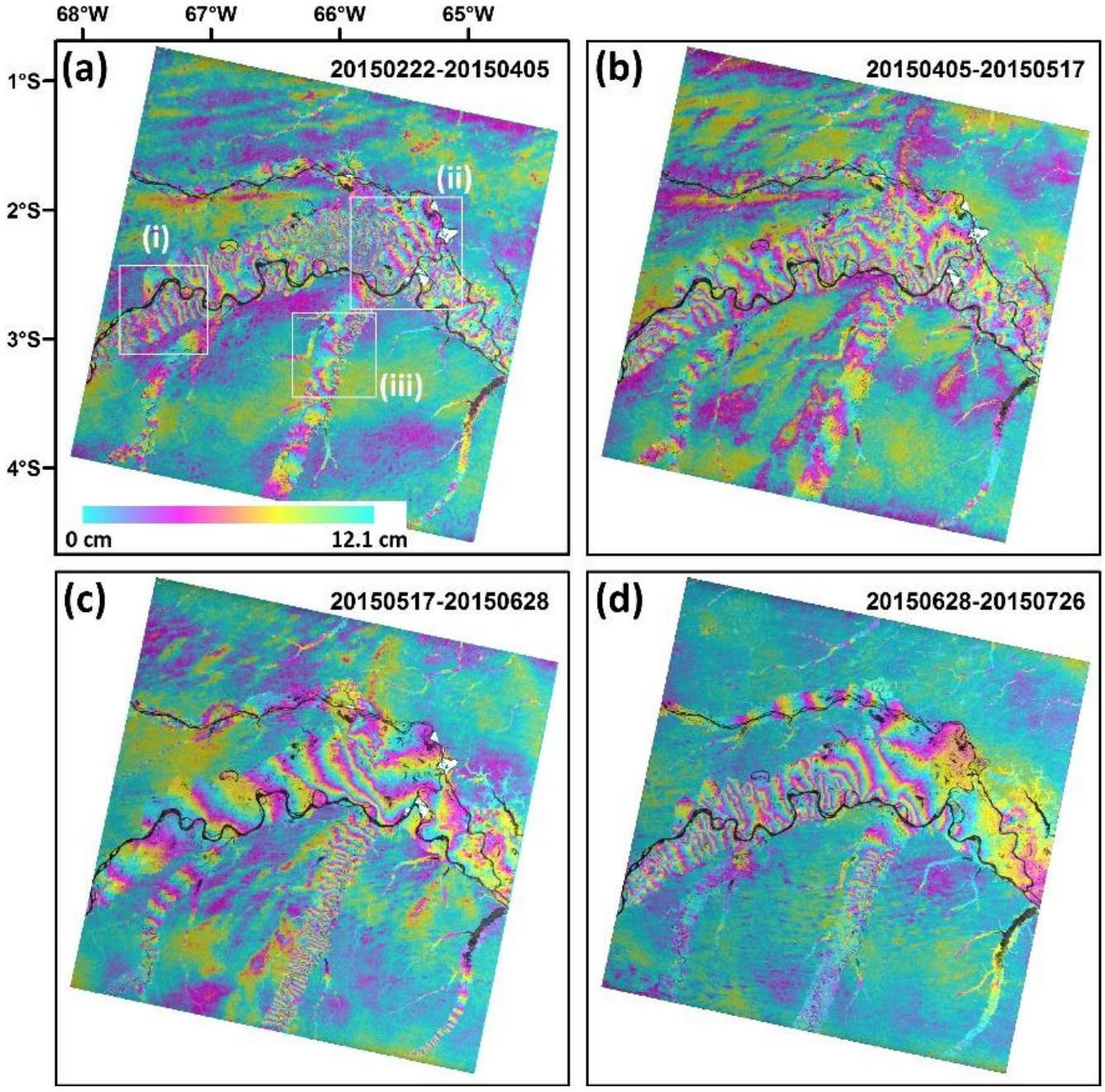

Figure 9. Final wrapped differential interferograms. Three white rectangles in (a) are zoomed in as shown in Figure 10. The time span between master and slave dates for the four interferograms are 42 , 42,42 , and 28 days, respectively.

The change of $\partial \mathrm{h} / \partial \mathrm{t}$ patterns with water levels can be easily seen in the zoomed-in areas, as shown in Figure 10. For example, the complex geomorphology can be seen in Figure 10(i.a) around the area with high elevation (i.e., scroll bars), where the $\partial \mathrm{h} / \partial \mathrm{t}$ pattern is complex, as shown in Figure 10(i.b). The water level continues to rise and fills the depressions between April and May. Compared with Figure 10(i.b), the $\partial \mathrm{h} / \partial \mathrm{t}$ pattern of Figure 10(i.c) becomes less complex, especially for the scroll bars. During high water, the $\partial \mathrm{h} / \partial \mathrm{t}$ pattern of Figure 10(i.d) becomes uniformly distributed. Moreover, the color pattern of the interferometric fringes is inversed since the water level is falling. As the water continues to fall, the $\partial \mathrm{h} / \partial \mathrm{t}$ pattern becomes complex and related to the topography again, as shown in Figure 10(i.e).

The $\partial \mathrm{h} / \partial \mathrm{t}$ patterns of the floodplains are also shown by arrows in Figure 10. Black arrows indicates positive $\partial \mathrm{h} / \partial \mathrm{t}$ of rising water while white arrows are for negative $\partial \mathrm{h} / \partial \mathrm{t}$ of falling water. The sign of $\partial \mathrm{h} / \partial \mathrm{t}$ is determined by the absolute $\partial \mathrm{h} / \partial \mathrm{t}$ results in Section 3.3. The arrows point toward directions with larger water level changes. Therefore, black arrows point toward directions that accumulate more water and white arrows point toward directions that depart more water. From Figure 10i, we can see that both black and white arrows point toward upstream, which means the upstream receives more water in the rising water season while departing more water in the falling water season. For Figure 10(ii.b,ii.d), directions of the black arrows change for different periods, 
which can be caused by the sources of water flows being different when water fills the floodplains from rivers. From Figure 10(iii.b), we can see the spatial patterns of the overbank flow from the river to the floodplains. For Figure 10(iii.b,iii.e), arrows uniformly point toward upstream, which means the upstream departs more water than the downstream.

It is known that $\partial \mathrm{h} / \partial \mathrm{t}$ equals to spatial changes in discharge (i.e., $\partial \mathrm{h} / \partial \mathrm{t} \approx-\nabla \mathrm{Q}$, where $\mathrm{Q}$ is the water discharge) [22]. For rising water with positive $\partial \mathrm{h} / \partial \mathrm{t}$, water is assumed to be flowing to floodplain pockets with greater $\partial \mathrm{h} / \partial \mathrm{t}$ [22]. Based on this assumption, the black arrows in Figure 10 can also indicate the directions of water flow. However, such an assumption may not be accurate because of the inner channels in the floodplains. How to infer the directions of water flow from spatial variations in $\partial \mathrm{h} / \partial \mathrm{t}$ is beyond the scope of this paper.

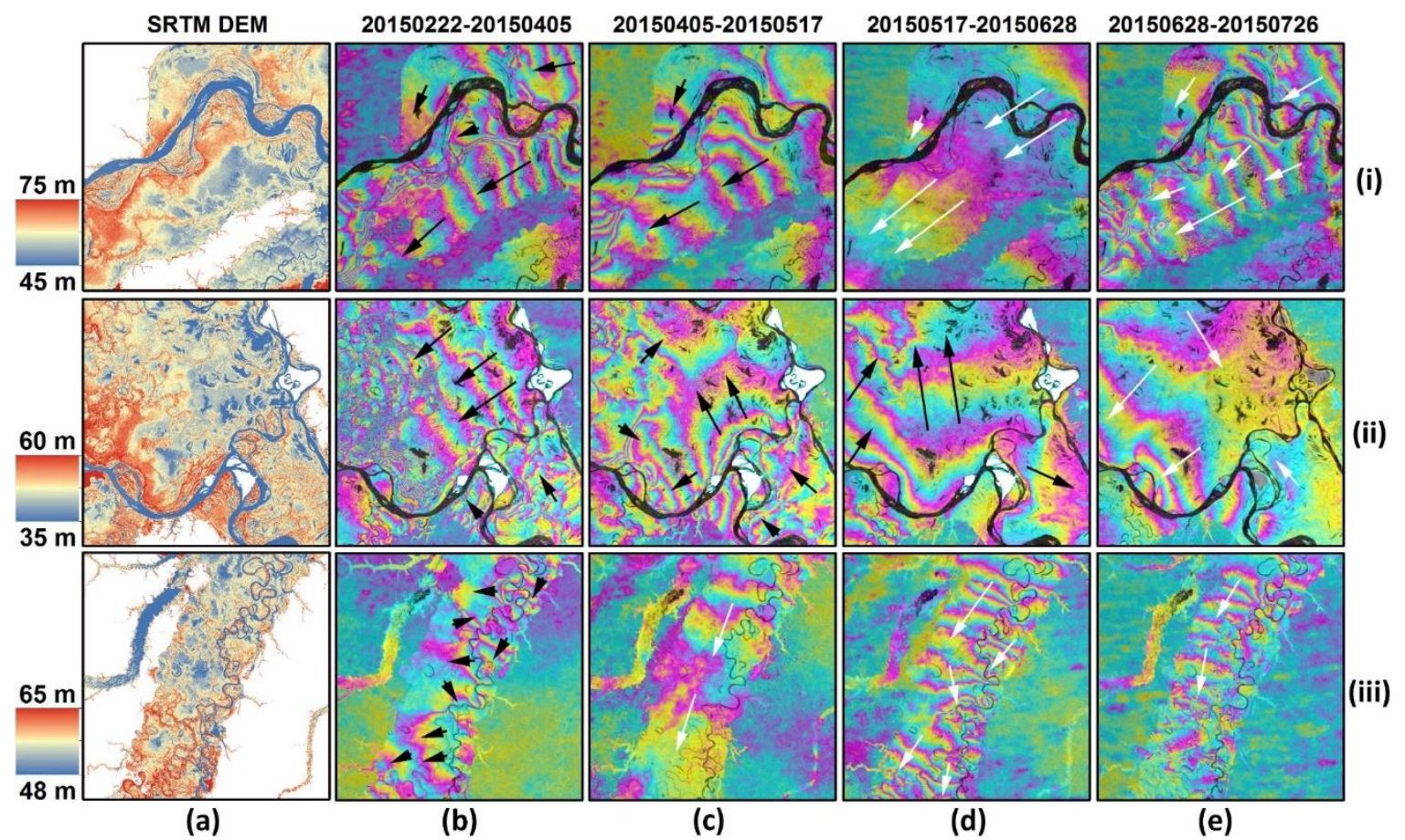

Figure 10. Differential interferograms for three zoomed-in areas (i), (ii), and (iii) labeled in Figure 9. SRTM DEMs are also included in (a).

\subsection{Interpretations of $\partial h / \partial t$ Patterns on a Large Scale}

The previous section investigated three zoomed segments of the study area in order to interpret $\partial \mathrm{h} / \partial \mathrm{t}$ patterns on a small scale. The results showed that the $\partial \mathrm{h} / \partial \mathrm{t}$ patterns of Amazon floodplains are spatially complex and localized for mid-rising and mid-falling water seasons. Similar conclusions have also been introduced in the previous studies using DInSAR with fine-beam datasets [21,22]. In this section, the $\partial \mathrm{h} / \partial \mathrm{t}$ patterns on a large scale observed from the ScanSAR datasets are presented.

The absolute $\partial \mathrm{h} / \partial \mathrm{t}$ maps can be obtained as shown in Figure 11. It should be noted that $\partial \mathrm{h} / \partial \mathrm{t}$ maps in Figure 11 use the altimetry measurements as references. The time series of the altimetry water height are interpolated for the SAR acquisition dates and $\partial \mathrm{h} / \partial \mathrm{t}$ references can be obtained for different DInSAR pairs. Since there are few in situ measurements available in the study area, the DInSAR results cannot be directly validated by true data. In order to verify the performance of DInSAR measurements, the comparisons of the DInSAR $\partial \mathrm{h} / \partial \mathrm{t}$ with altimetry $\partial \mathrm{h} / \partial \mathrm{t}$ along the SARAL tracks are shown in Figure 12. The DInSAR $\partial \mathrm{h} / \partial \mathrm{t}$ values are interpolated for the altimetry measurement points. We can see that the four DInSAR $\partial \mathrm{h} / \partial \mathrm{t}$ maps agree well with SARAL measurements, with root-mean-square errors (rmse) of $0.2 \mathrm{~m}, 0.1 \mathrm{~m}, 0.1 \mathrm{~m}$, and $0.1 \mathrm{~m}$, respectively. The bias of the comparison can be caused by the inconsistencies of the acquisition dates of DInSAR and altimetry. It should also be noted that 
such "cross validation" is only for DInSAR-altimetry agreement evaluation and is not a strict way to validate the DInSAR measurements.
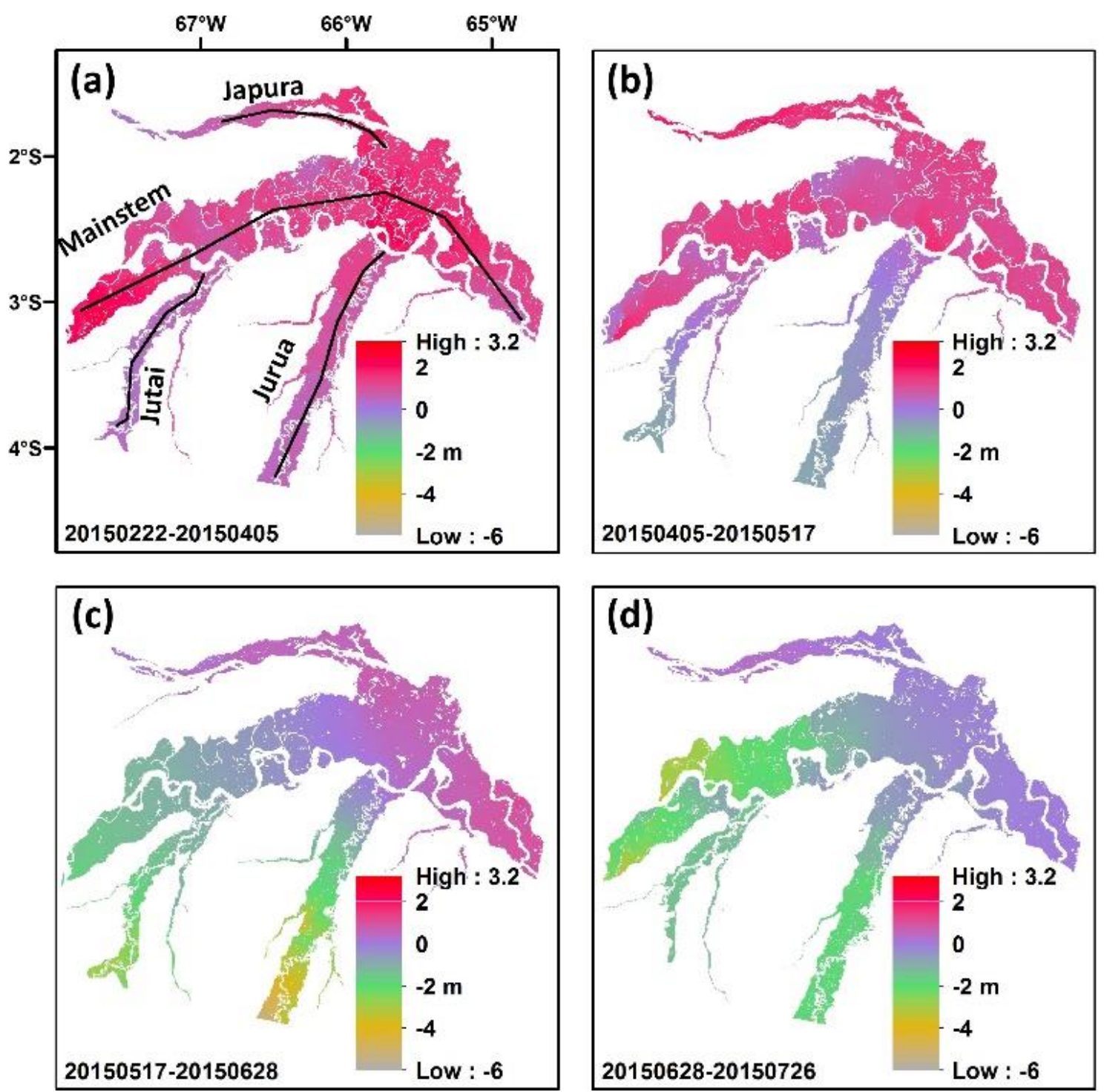

Figure 11. Final DInSAR $\partial \mathrm{h} / \partial \mathrm{t}$ maps. The black lines in (a) are profiles along the floodplains which will be examined for further analysis.

During the water increasing period (i.e., Figure 11a,b), the water level increases up to 3 $\mathrm{m}$. During the water decreasing period (i.e., Figure 11c,d), the water level decreases up to $4 \mathrm{~m}$. For different parts of the floodplains, the patterns of absolute $\partial \mathrm{h} / \partial \mathrm{t}$ are different. The water levels of the Jutai and Jurua floodplains mainly increase between February and April and decrease significantly after mid-May. For the Japura floodplain, the water level mainly increases in Figure $11 \mathrm{~b}$ and starts to decrease in Figure 11d. For the mainstem floodplain, the water level increases dramatically between February and mid-May. Compared with the upstream floodplain, the water level in the downstream floodplain along the mainstem floodplain decreases less, as shown in Figure 11c,d, which can be caused by the late arrival of the peak stages of the Japura River, as shown in Figure 9b. 

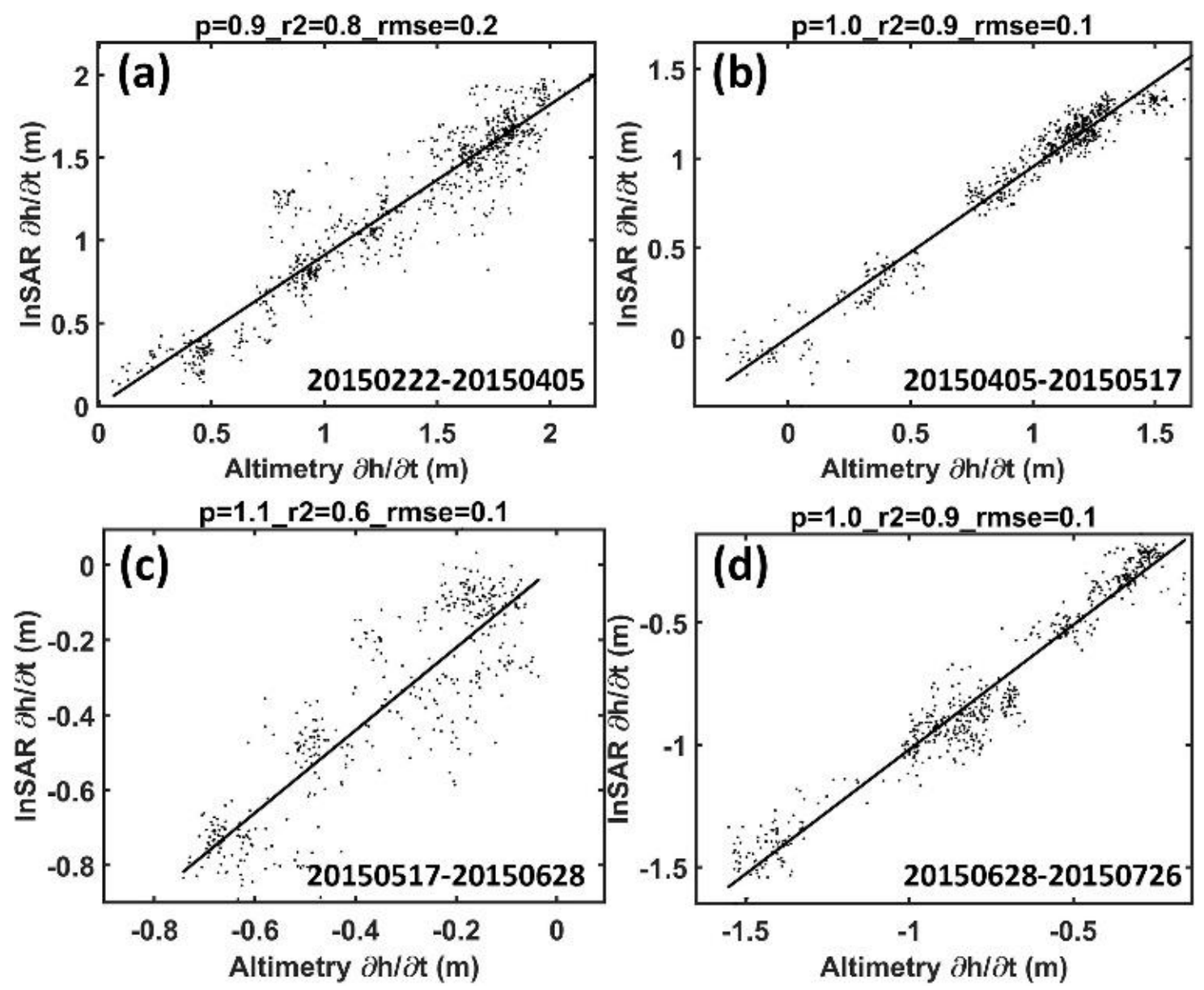

Figure 12. Comparison of DInSAR $\partial \mathrm{h} / \partial \mathrm{t}$ with altimetry $\partial \mathrm{h} / \partial \mathrm{t}$. The parameters $\mathrm{p}$ and $\mathrm{r} 2$ represent the slopes of the least-square fitted lines and $R^{2}$ values, respectively.

In order to further analyze the $\partial \mathrm{h} / \partial \mathrm{t}$ patterns on a large scale, the $\partial \mathrm{h} / \partial \mathrm{t}$ along the four arbitrarily chosen center profiles of the mainstem, Japura, Jutai, and Jurua floodplains are shown in Figures 13-16, respectively. Figure 13a shows that the upstream and downstream of the mainstem floodplain have dramatic water increases of $\sim 2 \mathrm{~m}$ between February and April. As shown in Figure 13b, the water level continuously increases about $1 \mathrm{~m}$ and there exist abrupt $\partial \mathrm{h} / \partial \mathrm{t}$ changes around the longitude of $-67^{\circ}$ where the profile crosses the Amazon River. Such abrupt changes have also been observed in previous studies and are spatially coincident with floodplain channels [22]. We can see from Figure $13 \mathrm{c}$ that the $\partial \mathrm{h} / \partial \mathrm{t}$ values gradually increase from upstream to downstream, which verifies that the mainstem floodplain has smooth $\partial \mathrm{h} / \partial \mathrm{t}$ patterns extending uniformly across the floodplain at high water. In Figure $13 \mathrm{~d}$, the abrupt $\partial \mathrm{h} / \partial \mathrm{t}$ change reoccurs around longitude $-67^{\circ}$ as the water level decreases. In spite of the abrupt $\partial \mathrm{h} / \partial \mathrm{t}$ changes around the river, the $\partial \mathrm{h} / \partial \mathrm{t}$ patterns are smoothly distributed from upstream to downstream. From Figure 13c,d, we can observe larger upstream water level changes than downstream during water falling period.

We can see from Figure $14 \mathrm{a}-\mathrm{c}$ that the water level of the Jupura floodplain continuously increases from February to the end of June. However, the $\partial \mathrm{h} / \partial \mathrm{t}$ patterns are interestingly different for different periods. Figure 14a shows that the downstream of the Jupura floodplain has larger $\partial \mathrm{h} / \partial \mathrm{t}$ than the upstream from February to April. On the contrary, Figure 14b shows that the $\partial \mathrm{h} / \partial \mathrm{t}$ of the upstream becomes larger than the downstream from April to mid-May. Figure $14 \mathrm{c}$ indicates that $\partial \mathrm{h} / \partial \mathrm{t}$ is around $0.5 \mathrm{~m}$ for both upstream and downstream from mid-May to the end of June. From Figure 14d, we can see that the water level of the downstream starts to fall while the upstream still shows slightly increasing water. 

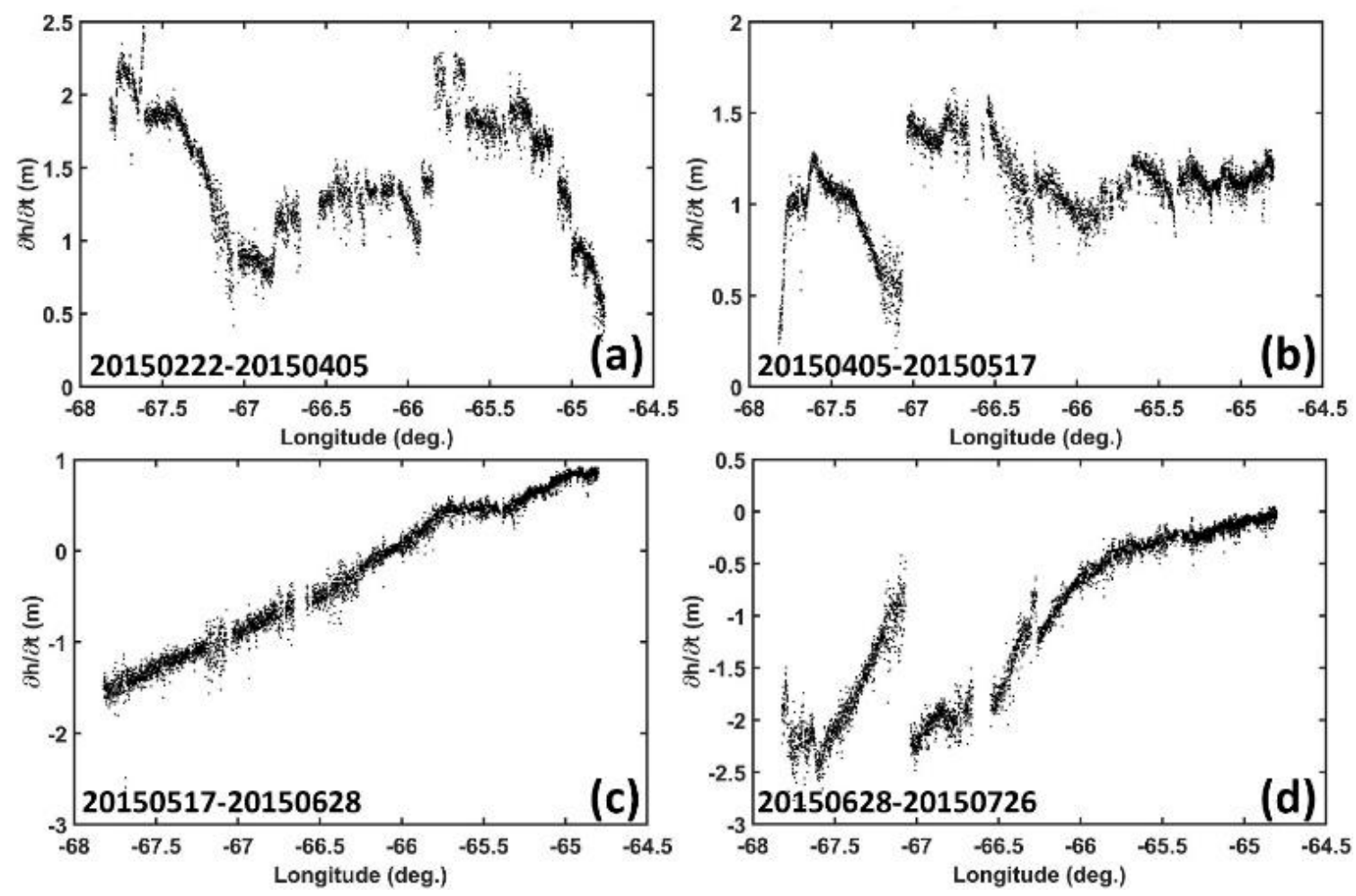

Figure 13. DInSAR $\partial \mathrm{h} / \partial \mathrm{t}$ along the center profile of the mainstem floodplain shown in Figure 11a.
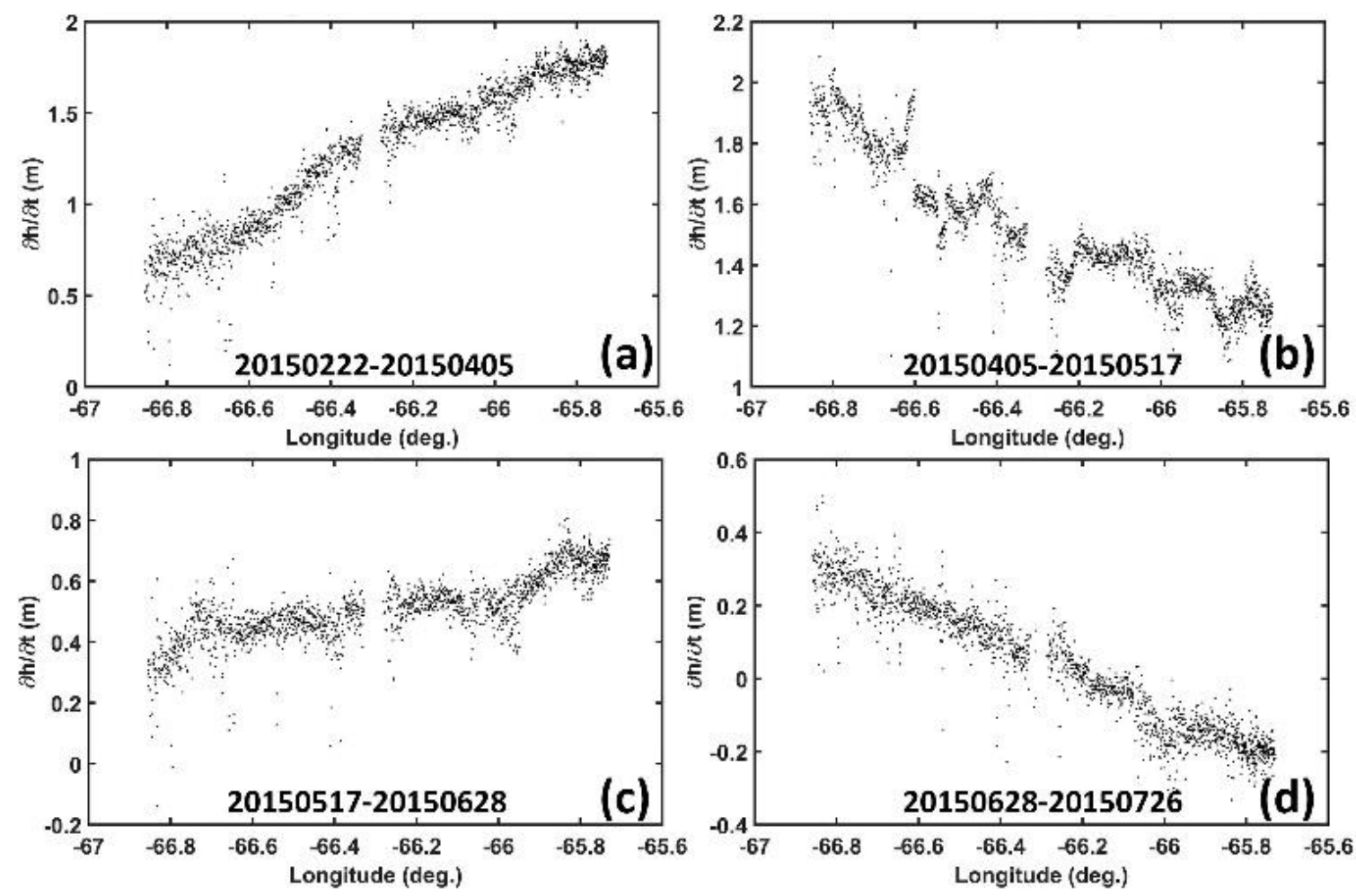

Figure 14. DInSAR $\partial \mathrm{h} / \partial \mathrm{t}$ along the center profile of the Japura floodplain shown in Figure 11a. 

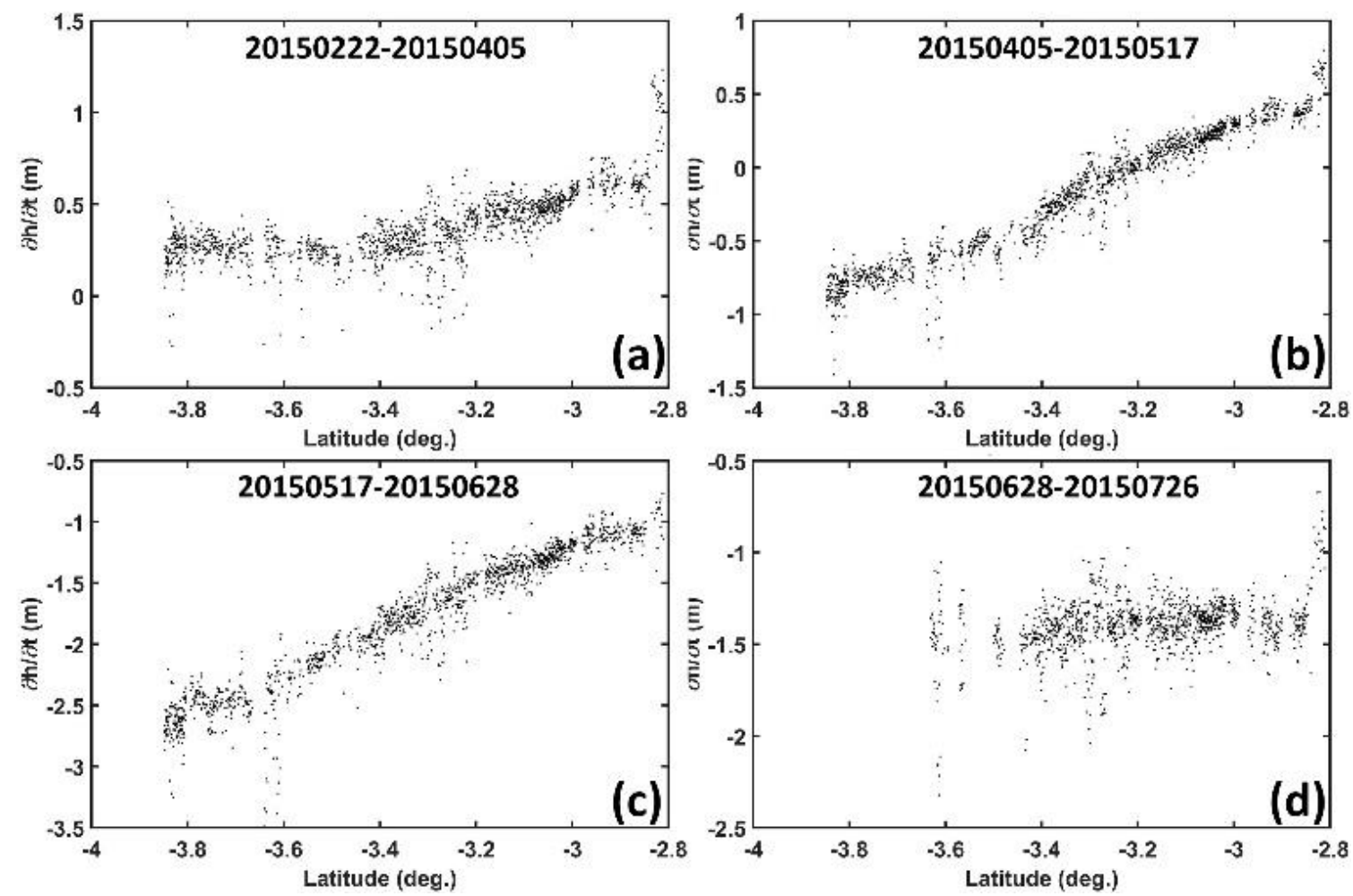

Figure 15. DInSAR $\partial \mathrm{h} / \partial \mathrm{t}$ along the center profile of the Jutai floodplain shown in Figure 11a.

Comparing Figures 15 and 16, we can see that the $\partial \mathrm{h} / \partial \mathrm{t}$ patterns of the Jutai and Jurua floodplains are similar along the center profiles. Both Figures 15a and 16a show that the downstream has a slightly larger water level increase than the upstream. Even though the $\partial \mathrm{h} / \partial \mathrm{t}$ of the Jurua floodplain fluctuates in Figure 16a, the general pattern is that $\partial \mathrm{h} / \partial \mathrm{t}$ increases from upstream to downstream. In other words, the $\partial \mathrm{h} / \partial \mathrm{t}$ patterns of Figure 16a are complex in local scale and have a simple increasing trend on a large scale. We can see from Figures $15 \mathrm{~b}$ and $16 \mathrm{~b}$ that the water of the upstream falls dramatically while the downstream still slightly accumulates water from April to mid-May. From Figures 15c and $16 \mathrm{c}$, we can see that the water level falls dramatically between mid-May and the end of June and the upstream decreases more than the downstream. Figures $15 \mathrm{~d}$ and $16 \mathrm{~d}$ show that the water level continuously decreases from the end of June to July. In general, we can see that the downstream has a larger $\partial \mathrm{h} / \partial \mathrm{t}$ during the water increasing period and the upstream has a larger absolute $\partial \mathrm{h} / \partial \mathrm{t}$ during water falling period. Moreover, compared with the mainstem floodplain, the three tributaries have much simpler $\partial \mathrm{h} / \partial \mathrm{t}$ patterns.

In summary, from the above analysis, we can see that the large-scale $\partial \mathrm{h} / \partial \mathrm{t}$ pattern can be much simpler even though the local $\partial \mathrm{h} / \partial \mathrm{t}$ patterns are complex, as shown in Section 3.2. Therefore, it is beneficial to analyze both the large-scale and local $\partial \mathrm{h} / \partial \mathrm{t}$ pattern of Amazon floodplains using ScanSAR datasets. It should be noted that the quantitative accuracy analysis of the above DInSAR results cannot be provided due to the limited in situ measurements. 

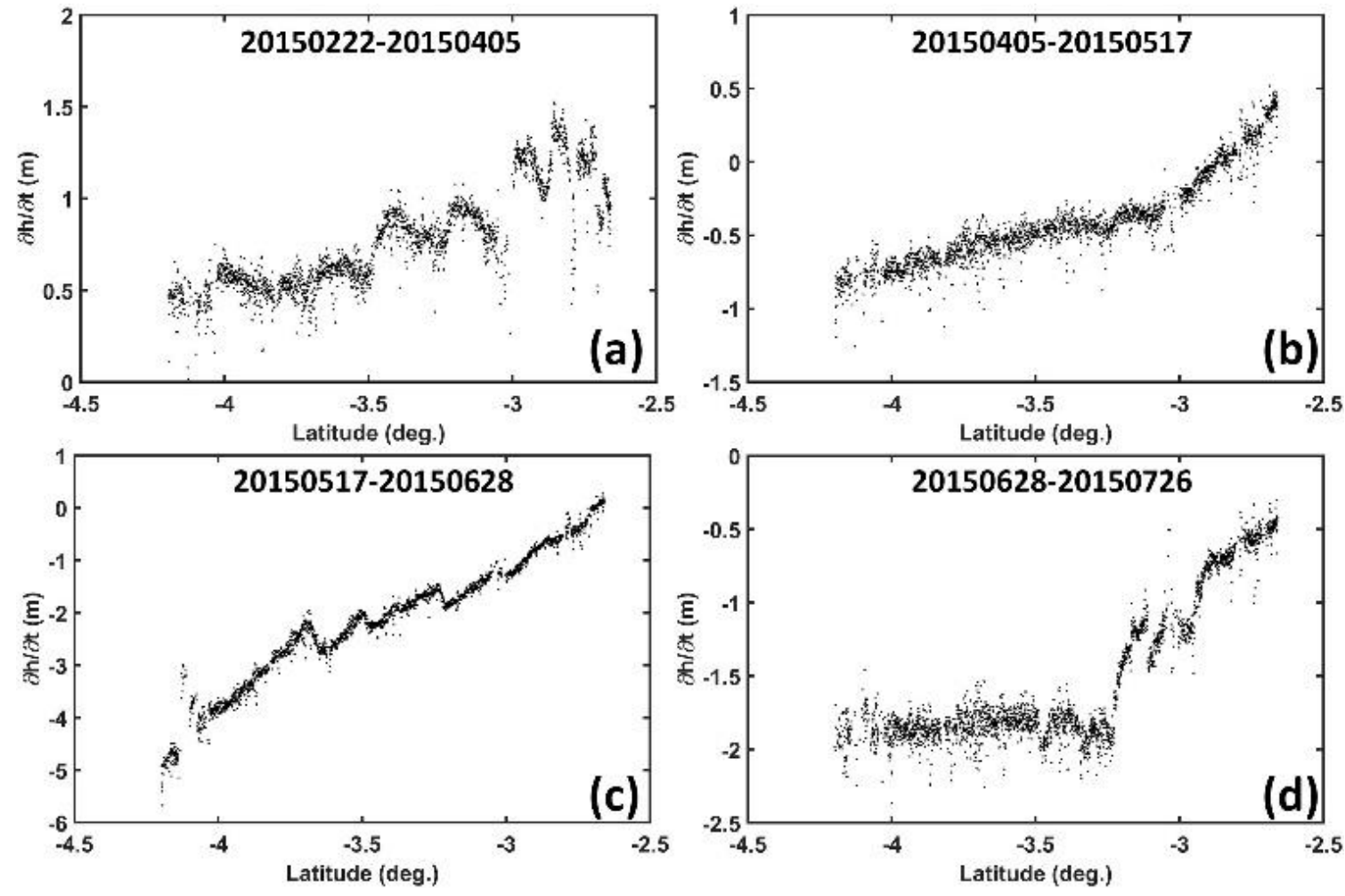

Figure 16. DInSAR $\partial \mathrm{h} / \partial \mathrm{t}$ along the center profile of the Jurua floodplain shown in Figure 11a.

\section{Conclusions}

The spatial resolution and coherence of fine-beam DInSAR are generally better than ScanSAR DInSAR, which means the fine-beam DInSAR can capture more accurate spatial variation of the $\partial \mathrm{h} / \partial \mathrm{t}$ patterns and get better $\partial \mathrm{h} / \partial \mathrm{t}$ estimate accuracy. However, the large-scale $\partial \mathrm{h} / \partial \mathrm{t}$ patterns cannot be directly obtained from mosaicking fine-beam images since $\partial \mathrm{h} / \partial \mathrm{t}$ changes rapidly in floodplains. Therefore, even though the accuracy of the ScanSAR estimate is not as good as the fine-beam data, it is still necessary for processing ScanSAR datasets to obtain large-scale $\partial \mathrm{h} / \partial \mathrm{t}$ maps. In this paper, for the first time, we demonstrated how to use ALOS2 ScanSAR data to acquire large-scale water level changes $(\partial \mathrm{h} / \partial \mathrm{t})$ in Amazon wetlands. The basic procedures of DInSAR processing are given. The major difficulties caused by orbit error, ionospheric error, and phase unwrapping in ScanSAR DInSAR processing are also analyzed. Finally, four large-scale (with $350 \mathrm{~km}$ swath) two-dimensional $\partial \mathrm{h} / \partial \mathrm{t}$ maps are generated for year 2015. The obtained $\partial \mathrm{h} / \partial \mathrm{t}$ maps can provide reliable information to study the wetland storages and fluxes over the Amazon wetlands, which are critical in understanding their flow processes and biogeochemical cycles. The proposed procedures can also be used over other large-scale wetlands, such as the Congo wetland, which will be studied in the future.

Author Contributions: Ning Cao: Conceptualization; Data curation; Investigation; Methodology; Validation; Visualization; Writing - original draft. Hyongki Lee: Conceptualization; Supervision; Investigation; Validation. Hahn Chul Jung: Conceptualization; Investigation; Validation. Hanwen Yu: Methodology; Validation.

Funding: This paper is supported by NASA's New Investigator Program (NNX14AI01G), SWOT Science Team Project (NNX16AQ33G), and GEO Program (80NSSC18K0423).

Acknowledgments: The ALOS2 data are provided by Japan Aerospace Exploration Agency (JAXA) (PI No. 1976 \& 3069).

Conflicts of Interest: The authors declare no conflict of interest. 


\section{References}

1. Molinier, M.; Guyot, J.L.; Oliveira, E.; Guimaraes, V.; Chaves, A. Hydrologie du bassin de l'Amazone. In Grands bassins fluviaux périatlantiques: Congo, Niger; Actes du Colloque PEGI/INSU/CNRS, 22-24/11/1993; Amazone, J.B., Olivry, J.C., Eds.; ORSTOM: Paris, France, 1995; pp. 335-344.

2. Ronchail, J.; Guyot, J.L.; Villar, J.C.E.; Fraizy, P.; Cochonneau, G.; Oliveira, E.; Filizola, N.; Ordenez, J.J. Impact of the Amazon tributaries on major floods at Óbidos. In Climate Variability and Change: Hydrological Impacts; IAHS Publication Red book; Demuth, S., Gustard, A., Planos, E., Scatena, F., Servat, E., Eds.; IAHS: London, UK, 2006; pp. 220-225.

3. Paiva, R.C.D.; Buarque, D.C.; Collischonn, W.; Bonnet, M.-P.; Frappart, F.; Calmant, S.; Mendes, C.A.B. Large-scale hydrologic and hydrodynamic modeling of the Amazon River basin. Water Resour. Res. 2013, 49, 1226-1243. [CrossRef]

4. Paiva, R.C.D.; Collischonn, W.; Tucci, C.E.M. Large scale hydrologic and hydrodynamic modeling using limited data and a GIS based approach. J. Hydrol. 2011, 406, 170-181. [CrossRef]

5. Yamazaki, D.; Kanae, S.; Kim, H.; Oki, T. A physically based description of floodplain inundation dynamics in a global river routing model. Water Resour. Res. 2011, 47, W04501. [CrossRef]

6. Dunne, T.; Mertes, L.A.K.; Meade, R.H.; Richey, J.E.; Forsberg, B.R. Exchanges of sediment between the flood plain and channel of the Amazon River in Brail. Geol. Soc. Am. Bull. 1998, 110, 450-467. [CrossRef]

7. Melack, J.M.; Forsberg, B. Biogeochemistry of Amazon floodplain lakes and associated wetlands. In The Biogeochemistry of the Amazon Basin and its Role in a Changing World; McClain, M.E., Victoria, R.L., Richey, J.E., Eds.; Oxford University Press: Oxford, UK, 2001; pp. 235-276.

8. Hamilton, S.K.; Sippel, S.J.; Melack, J.M. Comparison of Inundation Patterns among Major South American Floodplains. J. Geophys. Res. 2002, 107, 8038. [CrossRef]

9. Melack, J.M.; Engle, D. An organic carbon budget for an Amazon floodplain lake. Verh. Internat. Verein. Limnol. 2009, 30, 1179-1182. [CrossRef]

10. Richey, J.E.; Melack, J.M.; Aufdenkampe, A.K.; Ballester, V.M.; Hess, L. Outgassing from Amazonian rivers and wetlands as a large tropical source of atmospheric carbon dioxide. Nature 2002, 416, 617-620. [CrossRef] [PubMed]

11. Melack, J.M.; Hess, L.L.; Gastil, M.; Forsberg, B.R.; Hamilton, S.K.; Lima, I.B.T.; Novo, E.M.L.M. Regionalization of methane emissions in the Amazon basin with microwave remote sensing. Glob. Chang. Boil. 2004, 10, 530-544. [CrossRef]

12. Melack, J.M. Aquatic ecosystems. In Interactions between Biosphere, Atmosphere and Human Land Use in the Amazon Basin. Ecological Studies 227; Nagy, L., Forsberg, B., Artaxo, P., Eds.; Springer: Berlin, Germany, 2016; pp. 117-145.

13. Alsdorf, D.E.; Lettenmaier, D.P. Tracking fresh water from space. Science 2003, 301, 1485-1488. [CrossRef] [PubMed]

14. Yamazaki, D.; Sato, T.; Kanae, S.; Hirabayashi, Y.; Bates, D.P. Regional flood dynamics in a bifurcating mega delta simulated in a global river model. Geophys. Res. Lett. 2014, 41, 3127-3135. [CrossRef]

15. Pontes, P.R.M.; Fan, F.M.; Fleischmann, A.S.; Paiva, R.C.D.; Buarque, D.C.; Siqueira, V.A.; Jardim, P.F.; Sorribas, M.V.; Collischonn, W. MGB-IPH model for hydrological and hydraulic simulation of large floodplain river systems coupled with open source GIS. Environ. Model. Softw. 2017, 94, 1-20. [CrossRef]

16. Rosen, P.A.; Hensley, S.; Joughin, I.R.; Li, F.K.; Madsen, S.N.; Rodriguez, E.; Goldstein, M.R. Synthetic aperture radar interferometry. Proc. IEEE 2000, 88, 333-382. [CrossRef]

17. Bamler, R.; Hartl, P. Synthetic aperture radar interferometry. Inv. Probl. 1998, 14, R1-R54. [CrossRef]

18. Alsdorf, D.E.; Melack, J.M.; Dunne, T.; Mertes, L.A.K.; Hess, L.L.; Smith, L.C. Interferometric radar measurements of water level changes on the Amzon floodplain. Nature 2000, 404, 174-177. [CrossRef] [PubMed]

19. Alsdorf, D.E.; Birkett, C.; Dunne, T.; Melack, J.M.; Hess, L. Water level changes in a large Amazon lake measured with spaceborne radar interferometry and altimetry. Geophys. Res. Lett. 2001, 28, 2671-2674. [CrossRef]

20. Alsdorf, D.E.; Smith, L.C.; Melack, J.M. Amazon Floodplain Water Level Changes Measured with Interferometric SIR-C Radar. IEEE Trans. Geosci. Remote Sens. 2001, 39, 423-431. [CrossRef] 
21. Jung, H.C.; Hamski, J.; Durand, M.; Alsdorf, D.; Hossain, F.; Lee, H.; Hossain, A.K.M.A.; Hasan, K.; Khan, A.S.; Hoque, A.K.M.Z. Characterization of complex fluvial systems via remote sensing of spatial and temporal water level variations in the Amazon, Congo, and Brahmaputra Rivers. Earth Surf. Process. Landforms 2010, 35, 294-304. [CrossRef]

22. Alsdorf, D.E.; Bates, P.; Melack, J.; Wilson, M.; Dunne, T.B. Spatial and temporal complexity of the Amazon flood measured from space. Geophys. Res. Lett. 2007, 34. [CrossRef]

23. Alsdorf, D.E.; Beighley, E.; Laraque, A.; Lee, H.; Tshimanga, R.; O’Loughlin, F.; Mahé, G.; Dinga, B.; Moukandi, G.; Spencer, R.G.M. Opportunities for hydrologic research in the Congo Basin. Rev. Geophys. 2016, 54, 378-409. [CrossRef]

24. Yuan, T.; Lee, H.; Jung, H.C. Congo floodplain hydraulics using PALSAR InSAR and Envisat altimetry data. In Remote Sensing of Hydrological Extremes; Springer: Berlin, Germany, 2017; pp. 65-81.

25. Yuan, T.; Lee, H.; Jung, H.C.; Aierken, A.; Beighley, E.; Alsdorf, D.; Tshimanga, R.; Kim, D. Absolute water storages in the Congo River floodplains from integration of InSAR and satellite radar altimetry. Remote Sens. Environ. 2017, 201, 57-72. [CrossRef]

26. Jung, H.C.; Alsdorf, D. Repeat-pass multi-temporal interferometric SAR coherence variations with Amazon floodplain and lake habitats. Int. J. Remote Sens. 2010, 31, 881-901. [CrossRef]

27. Salvia, M.; Grings, F.; Ferrazzoli, P.; Barraza, V.; Douna, V.; Perna, P.; Karszenbaum, H. Estimating flooded area and mean water level using active and passive microwaves: The example of Paran River delta floodplain. Hydrol. Earth Syst. Sci. Discuss. 2011, 8, 2895-2928. [CrossRef]

28. Grings, F.M.; Ferrazzoli, P.; Jacobo-Berlles, J.C.; Karszenbaum, H.; Tiffenberg, J.; Pratolongo, P.; Kandus, P. Monitoring flood condition in marshes using EM models and Envisat ASAR observations. IEEE Trans. Geosci. Remote Sens. 2006, 44, 936-942. [CrossRef]

29. Kim, J.W.; Lu, Z.; Gutenberg, L.; Zhu, Z. Characterizing hydrologic changes of the Great Dismal Swamp using SAR/InSAR. Remote Sens. Environ. 2017, 198, 187-202. [CrossRef]

30. Neumann, M.; Saatchi, S.S.; Ulander, L.M.H.; Fransson, R.E.S. Assessing performance of L- and P-band polarimetric interferometric SAR data in estimating boreal forest above-ground biomass. IEEE Trans. Geosci. Remote Sens 2012, 50, 714-726. [CrossRef]

31. Kasischke, E.S.; Tanase, M.A.; Bourgeau-Chavez, L.L.; Borr, M. Soil moisture limitations on monitoring boreal forest regrowth using spaceborne L-band SAR data. Remote Sens. Environ. 2011, 115, 227-232. [CrossRef]

32. Kim, J.-W.; Lu, Z.; Lee, H.; Shum, C.K.; Swarzenski, C.M.; Doyle, T.W.; Baek, S.-H. Integrated Analysis of PALSAR/Radarsat-1 InSAR and ENVISAT Altimeter Data for Mapping of Absolute Water Level Changes in Louisiana Wetlands. Remote Sens. Environ. 2009, 113, 2356-2365. [CrossRef]

33. Bronner, E.; Gulliot, A.; Picot, N.; Noubel, J. SARAL/AltiKa Products Handbook; SALP-MU-M-OP-15984-CN; Centre National d'Etudes Spatiales: Toulouse, France, 2013.

34. Japan Aerospace Exploration Agency. ALOS Data Users Handbook; Revision C; Japan Aerospace Exploration Agency: Tokyo, Japan, 2008.

35. Lee, H.; Yuan, T.; Jung, H.C.; Beighley, E. Mapping wetland water depths over the central Congo Basin using PALSAR ScanSAR, envisat altimetry, and MODIS VCF data. In Remote Sensing of Environment; Elsevier: New York City, NY, USA, 2014.

36. Arnesen, A.S.; Silva, T.S.F.; Hess, L.L.; Novo, E.M.L.M.; Rudorff, C.M.; Chapman, B.D.; McDonald, K.C. Monitoring flood extent in the Lower Amazon River floodplain using ALOS/PALSAR ScanSAR images. Remote. Sens. Environ. 2013, 130, 51-61. [CrossRef]

37. Bamler, R.; Eineder, M. ScanSAR processing using standard high precision SAR algorithms. IEEE Trans. Geosci. Remote Sens. 1996, 34, 212-218. [CrossRef]

38. Krieger, G.; Hajnsek, I.; Papathanassiou, K.; Eineder, M.; Younis, M.; de Zan, F.; Huber, S.; Lopez-Dekker, P.; Prats, P.; Werner, M. Tandem-L: An innovative interferometric and polarimetric SAR mission to monitor Earth system dynamics with high resolution. In Proceedings of the IEEE Geoscience and Remote Sensing Symposium (IGARSS), Honolulu, HI, USA, 25-30 July 2010; pp. 253-256.

39. Rosen, P.; Hensley, S.; Shaffer, S.; Edelstein, W.; Kim, Y.; Kumar, R.; Misra, T.; Bhan, R.; Satish, R.; Sagi, R. An update on the NASA-ISRO dual-frequency DBF SAR (NISAR) mission. In Proceedings of the 2016 IEEE International Geoscience and Remote Sensing Symposium (IGARSS), Beijing, China, 10-15 July 2016.

40. Liang, C.; Fielding, E.J. Interferometry with ALOS-2 fullaperture ScanSAR data. IEEE Trans. Geosci. Remote Sens. 2017, 55, 2739-2750. [CrossRef] 
41. Liang, C.; Fielding, E.J. Interferometric processing of ScanSAR data using stripmap processor: New insights from coregistration. IEEE Trans. Geosci. Remote Sens. 2016, 54, 4343-4354. [CrossRef]

42. Meyer, F.; Bamler, R.; Jakowski, N.; Fritz, T. The potential of low-frequency SAR systems for mapping ionospheric TEC distributions. IEEE Geosci. Remote Sens. Lett. 2006, 3, 560-564. [CrossRef]

43. Hanssen, R.F. Radar Interferometry: Data Interpretation and Error Analysis; Kluwer: Norwell, MA, USA, 2002.

44. Shim, J.S. Analysis of Total Electron Content (TEC) Variations in the Low- and Middle-Latitude Ionosphere. Ph.D. Thesis, Utah State University, Logan, UT, USA, 2009.

45. Fattahi, H.; Simons, M.; Agram, P. InSAR Time-Series Estimation of the Ionospheric Phase Delay: An Extension of the Split Range-Spectrum Technique. IEEE Trans. Geosci. Remote Sens. 2017, 55, 5984-5996. [CrossRef]

46. Brcic, R.; Parizzi, A.; Eineder, M.; Bamler, R.; Meyer, F. Estimation and compensation of ionospheric delay for SAR interferometry. In Proceedings of the 2010 IEEE International Geoscience and Remote Sensing Symposium, Honolulu, HI, USA, 25-30 July 2010; pp. 2908-2911.

47. Rosen, P.A.; Hensley, S.; Chen, C. Measurement and mitigation of the ionospheric in L-band interferometric SAR data. In Proceedings of the 2010 IEEE Radar Conference, Washington, DC, USA, 10-14 May 2010; pp. 1459-1463.

48. Gomba, G.; Parizzi, A.; Zan, F.D.; Eineder, M.; Bamler, R. Toward operational compensation of ionospheric effects in SAR interferograms: The split-spectrum method. IEEE Trans. Geosci. Remote Sens 2016, 54, 1446-1461. [CrossRef]

49. Gomba, G.; Rodriguez, F.; de Zan, F. Ionospheric Phase Screen Compensation for the Sentinel-1 TOPS and ALOS-2 ScanSAR Modes. IEEE Trans. Geosci. Remote Sens. 2017, 55, 223-235. [CrossRef]

50. Gomba, G.; de Zan, F. Bayesian Data Combination for the Estimation of Ionospheric Effects in SAR Interferograms. IEEE Trans. Geosci. Remote Sens. 2017, 55, 6582-6593. [CrossRef]

51. Liang, C.; Fielding, E.J. Measuring azimuth deformation with L-band ALOS-2 ScanSAR interferometry. IEEE Trans. Geosci. Remote Sens. 2017, 55, 2725-2738. [CrossRef]

52. Raucoules, D.; de Michele, M. Assessing ionospheric influence on L-band SAR data: Implications on coseismic displacement measurements of the 2008 Sichuan earthquake. IEEE Geosci. Remote Sens. Lett. 2010, 7, 286-290. [CrossRef]

53. Jung, H.S.; Lee, D.T.; Lu, Z.; Won, J.S. Ionospheric Correction of SAR Interferograms by Multiple-Aperture Interferometry. IEEE Trans. Geosci. Remote Sens. 2013, 51, 3191-3199. [CrossRef]

54. Chen, A.C.; Zebker, H.A. Reducing Ionospheric Effects in InSAR Data Using Accurate Coregistration. IEEE Trans. Geosci. Remote Sens. 2014, 52, 60-70. [CrossRef]

55. Goldstein, R.M.; Zebker, H.A.; Werner, C.L. Satellite radar interferometry: Two-dimensional phase unwrapping. Radio Sci. 1988, 23, 713-720. [CrossRef]

56. Rosen, P.A.; Werner, C.W.; Hiramatsu, A. Two-dimensional phase unwrapping of SAR interferograms by charge connection through neutral trees. In Proceedings of the IGARSS'94, Pasadena, CA, USA, 8-12 August 1994.

57. Yu, H.; Lee, H.; Yuan, T.; Cao, N. A novel method for deformation estimation based on multi-baseline InSAR phase unwrapping. IEEE Trans. Geosci. Remote Sens. 2018. to be published. [CrossRef]

58. Cao, N.; Yu, H.; Lee, H. A Multi-baseline InSAR Phase Unwrapping Method using Designed Optimal Baselines obtained by Motion Compensation Algorithm. IEEE Geosci. Remote Sens. Lett. 2018. to be published. [CrossRef]

(C) 2018 by the authors. Licensee MDPI, Basel, Switzerland. This article is an open access article distributed under the terms and conditions of the Creative Commons Attribution (CC BY) license (http://creativecommons.org/licenses/by/4.0/). 